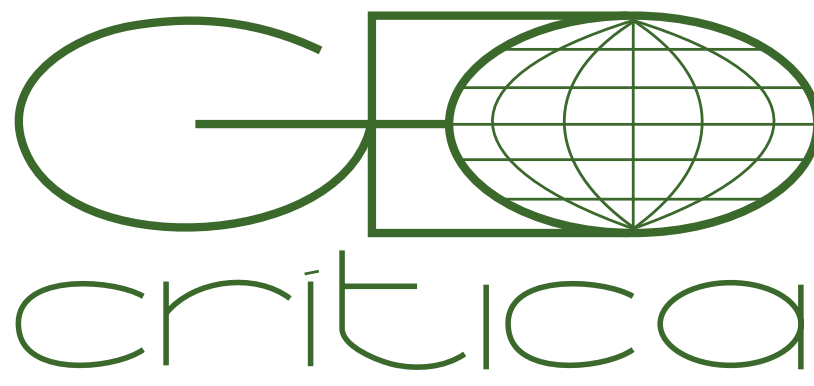

\section{Scripta Nova}

Revista Electrónica de Geografía y Ciencias Sociales Universitat de Barcelona

1 de Julio de 2020

\title{
EL BOSQUE DE LA PAMPA DEL TAMARUGAL Y LA INDUSTRIA SALITRERA: EL PROBLEMA DE LA DEFORESTACIÓN, LOS PROYECTOS PARA SU MANEJO SUSTENTABLE Y EL DEBATE POLÍTICO (TARAPACÁ, PERÚ-CHILE 1829-1941)
}

\author{
Luis Castro Castro \\ Universidad de Tarapacá \\ quismalc@yahoo.com
}

Este artículo forma parte de los proyectos FONDECYT 1140159 CYT-Chile. El ciclo 1829-1875 fue presentado en el VIII Congreso de Historia Nacional del Perú, Universidad Nacional de San Agustín Arequipa agosto de 2018. Agradezco al Dr. Jesús Raúl Navarro Garcia de la Escuela de Estudios Hispano-Americanos del CSIC-Sevilla y a la Dra. Inmaculada Simó Ruiz del Instituto de Estudios Husidad Autónoma de Chila por comentarios y sugerencias. Igual mente, al Dr. Sergio González de a Universidad de Tarapacá Sede quique, al Dr. Carlos Donoso de a Universidad de Tarapacá Sede Arica, a Fernando Aravena de la CONAF Región de Tarapaca y Hrvoj Ostojic del Centro Cultura Dona Vicenta de lquique, quienes mentación y material gráfico. Por ultimo a Gonzalo Catalán que elaboró el mapa para este artículo a los evaluadores que con sus observaciones permitieron mejorar la versión final de este trabajo. No obstante, las aseveraciones, uicios y conclusiones son de mi
Recibido: 23 octubre 2018; Devuelto para correciones: 27 agosto 2019; Aceptado: 17 noviembre 2019

El bosque de la Pampa del Tamarugal y la industria salitrera: el problema de la deforestación, los proyectos para su manejo sustentable y el debate político (Tarapacá, Perú-Chile 1829-1941) (Resumen)

Mediante la revisión de documentación administrativa, informes impresos y periódicos, en este artículo se describe y analiza la problemática de la deforestación de la Pampa del Tamarugal ocasionada por las faenas mineras del salitre ocurrida entre inicios del siglo XIX y comienzos del XX, poniendo atención tanto en el debate político medioambiental como en los esfuerzos desplegados por algunos funcionarios gubernamentales, ciertos empresarios y una parte de la opinión pública para salvar el bosque de tamarugos y algarrobos mediante la implementación de precursoras medidas político-administrativas y técnico-legales de manejo y protección.

Palabras clave: Pampa del Tamarugal, deforestación, proyectos de irrigación, propuestas de manejo y protección de los recursos forestales, debate político.

\section{The Forest of Pampa del Tamarugal and the Saltpeter Industry: The} Deforestation Problem, the Projects for their Sustainable Management and the Political Debate (Tarapacá, Perú-Chile 1829-1941) (Abstract)

Through the review of administrative documentation, printed reports and newspapers, this article describes and analyzes the problems of deforestation in Pampa del Tamarugal generated by the saltpeter mining operations between the beginning of the 19th century and the first decades of the 20th century, focusing both on the environmental policy debate and the efforts made by some government officials, some business owners and a part of the public opinion to save the tamarugo and algarrobo forest through the implementation of political-administrative and technical-legal measures for management and protection.

Keywords: Pampa del Tamarugal, deforestation, irrigation projects, management and protection proposals of forest resources, political debate. 
La Pampa del Tamarugal se ubica actualmente en la Región de Tarapacá, al extremo norte de Chile, unidad político-administrativa que hasta fines de la década de 1870 formó el área más meridional del Perú y que pasó a ser parte del territorio chileno tras el tratado de Ancón del 20 de octubre de 1883 que puso fin a la Guerra del Pacífico'.

Geográficamente es una sección del desierto de Atacama y, casi en su totalidad, ocupa la unidad fisiográfica denominada depresión intermedia². Morfológicamente conforma una cuenca endorreica (también descrita como valle longitudinal, llanura o depresión central) de 30 a 40 kilómetros de ancho y algo más de 400 kilómetros de largo ${ }^{3}$. Al norte limita con la quebrada de Tiliviche, llamada igualmente Berenguela o Retamilla; y al sur con el río Loa o quebrada de Quillagua (Ver imagen 1). Al poniente, producto del proceso de capilaridad, corre una franja dominada por salares que son ricos en yacimientos de nitrato de sodio o salitre; al oriente, en tanto, se despliega una zona que, por la influencia de las napas freáticas, se caracteriza por la presencia de un monte o bosque conformado por árboles, del género Prosopis, adaptados a un medio ambiente seco, salino y pobre en agua superficial. En su conjunto, posee una elevación que varía desde los 1.000 a los 1.500 metros sobre el nivel del mar5.

Su superficie está nivelada y aglomerada por la acumulación de sedimentos o material de arrastre tanto por la acción fluvial intermitente que proviene de la cordillera de Los Andes a través de las quebradas de Aroma, Tarapacá, Quipisca, Quisma, Chacarilla y Guatacondo, como por medio de precipitaciones ocasionales que ocurren principalmente en el período estival'. En estos términos, los mecanismos que aportan los escasos recursos hídricos a la cuenca endorreica son los ríos que surcan las quebradas, las precipitaciones en verano y las napas freáticas ${ }^{7}$. El clima predominante, de acuerdo a la clasificación de Köeppen, es el desértico normal con una fuerte oscilación térmica entre el día y la noche8. Del mismo modo, el rasgo plano de su superficie únicamente se ve interrumpido por los cerros Challacollo y Cerro Gordo o Challacollito que tienen una altitud que supera los 2.000 metros sobre el nivel del mar'.

Las especies que conforman el bosque de la Pampa del Tamarugal son el tamarugo (Prosopis tamarugo), el algarrobo chileno (Prosopis chilensis), el algarrobo blanco (Prosopis alba) y la fortuna (Prosopis strombulifera) ${ }^{10}$ (ver imágen 2). El tamarugo,

\footnotetext{
1 La Guerra del Pacífico o del Salitre duró cinco años (1879-1883) y enfrentó a Chile, que resultó vencedor, con Perú y Bolivia.

2 La Región de Tarapacá está constituida por 5 unidades fisiográficas de poniente a oriente: terraza costera, cordillera de la costa, depresión intermedia, precordillera o sierra y altiplano.

3 Armijo 1919, p. 291; Bertrand 1879, p. 4; Brüggen 1936, p. 6.

4 Billinghurst 1886, p. 28.

5 Velozo 1974, p. 102.

6 Este fenómeno es descrito con claridad a mediados del siglo XIX por la prensa de Iquique al comentar que, durante febrero de 1868, las lluvias "han sido abundantes en nuestra provincia, pues ha habido entradas de agua por todas las quebradas que se han derramado en la pampa del Tamarugal". El Mercurio de Tarapacá, Iquique 20/2/1868, p. 2.

7 Billinghurst 1886, p. 29; Brüggen 1936, p. 15-16; Velozo 1974, p. 104.

8 Velozo 1974, p. 3; Plan de Manejo Reserva Nacional Pampa del Tamarugal 1997, p. 35.

9 Billinghurst 1886, p. 40-41.

10 Carevic, Carevic y Delatorre 2012, p. 114.
} 


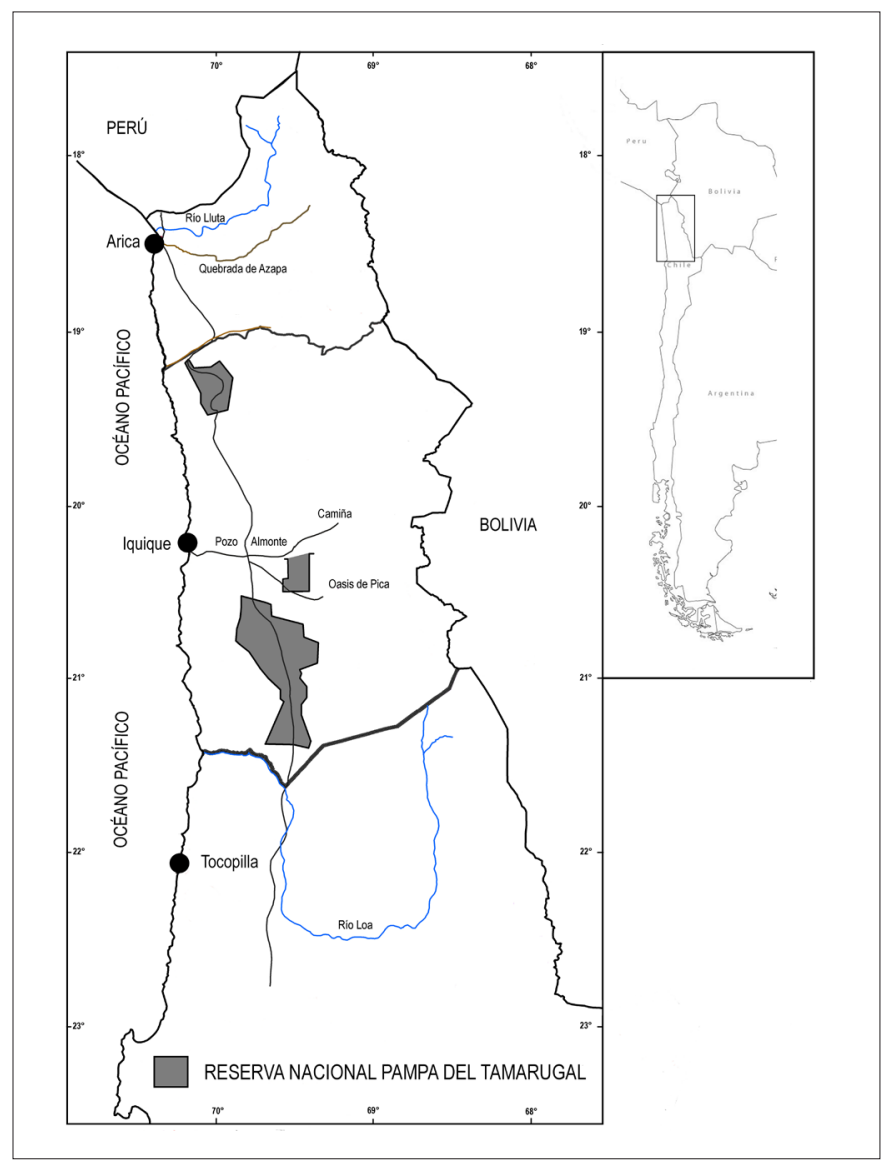

Imagen 1. Ubicación de la Pampa del Tamarugal y la actual Reserva Forestal.

Fuente: Elaboración propia.

árbol endémico que por ser el más característico y abundante le da el nombre a esta cuenca endorreica, llega a los 15 metros de altura, su época de floración es entre los meses de agosto a noviembre, su tronco tiene 1 metro de diámetro y la copa entre 15 a 20 metros $^{11}$. El algarrobo, en tanto, puede alcanzar entre 3 a 10 metros de altura (arbustivo, sub arbóreo y arbóreo grande), con una copa de 8 metros de diámetro y de tronco grueso y corto ${ }^{12}$. Ambas especies, además de la madera, leña y carbón, aportan frutos comestibles usados tanto para consumo humano como para alimentar el ganado.

El bosque de la Pampa del Tamarugal constituye en términos ambientales como culturales un recurso natural valioso, más aún tomando en cuenta que está situado en el desierto más árido del planeta, el de Atacama. Este rasgo fue aquilatado desde muy temprano por las poblaciones locales, las que comenzaron a emplear con distinta intensidad tanto la madera como los frutos de los árboles ${ }^{13}$. Si bien el usufructo utilitarista de esta biomasa fue persistente en el periodo precolombino, no fue sino hasta el periodo colonial que el bosque del Tamarugal comenzó a experimentar cierto deterioro a raíz de la demanda de leña y carbón por parte de la minería de la

11 Plan de Manejo Reserva Nacional Pampa del Tamarugal 1997, p. 36.

12 Burkart 1976.

13 Rivera 2018, p. 123-126. 


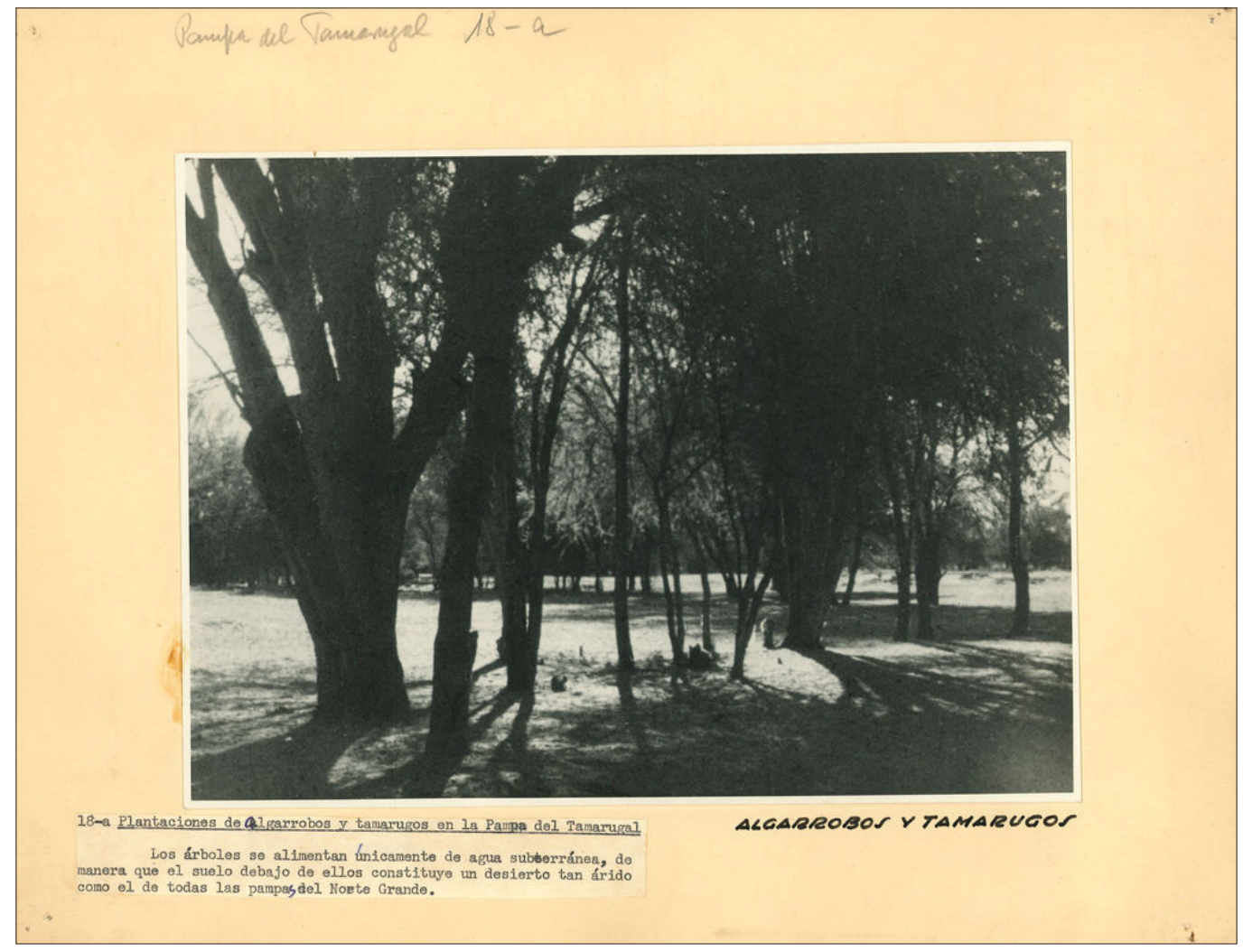

Imagen 2. Tamarugos y Algarrobos.

Fuente: Coleccion Documental Enciclopedia Chilena, ECH3344. En: www.ben.cl.

plata, situación que se intensificó sustancialmente durante el siglo XIX a causa de los requerimientos a gran escala de estos recursos por parte de la industria del salitre. Esta vinculación frágil entre el bosque, su potencial agrícola y la minería llevó a que desde el periodo colonial hubiesen intentos por trasvasar aguas cordilleranas hacia esta pampa ${ }^{14}$, pero no fue sino hasta la década de 1830 (producto de la aceleración del daño provocado por la demanda combinada de leña y carbón por parte de las minerías argentífera y salitrera) que se comenzó a vincular este tipo de iniciativas con la posibilidad de recuperar o tener un mejor manejo del bosque, lo que llevó a partir del decenio de 1840 a la formulación de interesantes y precursores proyectos gubernamentales y empresariales, además de la generación de un extendido debate.

El presente artículo indaga sobre estas iniciativas de recuperación y manejo del bosque nativo de la Pampa del Tamarugal, dando cuenta de la discusión pública y los argumentos políticos utilizados para criticar o validar las distintas propuestas en el contexto del ciclo salitrero, tratando de dejar en evidencia que este proceso configuró un momento relevante de la historia ambiental tanto de Perú como de Chile al generarse mecanismos (como incentivos para plantar árboles nativos y exóticos, control y fiscalización del comercio de la leña y el carbón y nombramiento de guardabosques) que todavía no son suficientemente conocidos dado que en el imaginario de peruanos y chilenos los bosques no son propios del desierto.

14 Castro 2004, p. 207-210. 


\section{Antecedentes históricos del uso de los árboles del desierto: desde el periodo precolombino a la época colonial}

El complejo y extenso desarrollo cultural de los grupos humanos que habitaron tempranamente el desierto de Atacama; fue un proceso que tuvo una correspondencia insoslayable con el entorno ecológico. En este desarrollo paulatino de logros tecnológicos que permitieron pasar de la subsistencia al manejo controlado de cultivos y animales, los recursos forestales tuvieron un rol relevante. El tamarugo, el algarrobo, el chañar (Geoflorea decorticans), el molle (Schimus patifolius) y el pacae (Inga feullet), no sólo representaron una diversidad en sí, sino también un acceso temprano a diferentes elementos utilizados para la alimentación y la construcción de artefactos y viviendas.

En el caso particular de la Pampa del Tamarugal y el área circundante los registros más antiguos, como Aragón I ( 3 kilómetros al norte de Zapiga) y Tiliviche 1-B ( 40 kilómetros al norte de Pisagua), delatan entre los 9.000 y los 6.000 a.C. una intensa actividad trashumante de recolección asociada a los tamarugos y algarrobos ${ }^{15}$. Hacia el formativo temprano, en tanto, se describe la existencia de grupos humanos en sitios de las quebradas de Tiliviche y Tarapacá que, entre los 3.000 a 2.000 a.C., tuvieron junto con las primeras experimentaciones del cultivo del maíz y la quinua ${ }^{16}$, una intensa recolección de vainas de algarrobo para la elaboración de harinas y bebidas fermentadas como de semillas del chañar para la elaboración de miel ${ }^{17}$. Una práctica que se intensificó en la fase más tardía de Alto Ramírez ${ }^{18}$. En el formativo tardío, 1.000 a.C. al 500 d.C., la consolidación del patrón de asentamiento sedentario asociado a una práctica intensiva de la agricultura y la ganadería, conllevó un incremento cualitativo de la utilidad de los árboles de la Pampa del Tamarugal, especialmente la ocupación de los troncos como vigas para levantar las residencias. Por ejemplo, en el campamento Caserones (25 kilómetros al este del pueblo de Huara) y en la aldea de Ramaditas (aledaña a la quebrada de Guatacondo) la madera de tamarugo fue el elemento más utilizado con este propósito, y en la llamada fase Azapa la elaboración de ambientes artificiales tuvo a los troncos de pacae como el recurso más empleado ${ }^{19}$. Finalmente, durante los horizontes medio y tardío, 400-1.200 y 1.400-1.532 d.C., los recursos asociados al bosque de la Pampa del Tamarugal pasaron a formar parte de la gran cantidad de bienes que se intercambiaron en los circuitos habilitados por los Tiwanakus y los Incas; además el bosque mismo comenzó a servir como lugar de descanso para los caravaneros y los frutos de los árboles como alimento para los animales de carga ${ }^{20}$.

Así, la interacción económica con el bosque desértico pasó a ser parte del modelo de adaptación de los grupos humanos hasta el contacto hispano. Desde este punto de vista, hay quienes incluso se inclinan a pensar que estos árboles y sus frutos pudieron

15 Carevic 1989, p. 1-2; Núñez y Moragas 1978; Santoro 1989, p. 35-47.

16 Núñez 1989, p. 90.

17 Carevic 1989, p. 2-3; Núñez 1989, p. 90; Martínez 1998, p. 110.

18 Muñoz 1989, p. 115.

19 Carevic,1989, p. 3; Núñez 1966; Muñoz 1989, p. 113; Rivera 2018, p. 123 y 128.

20 Berenguer y Dauelsberg 1989. 
haber ocupado una posición cultural similar a la que tuvieron el maíz y los tubérculos en los Andes centrales².

A la llegada de los españoles la masa arbórea de la Pampa del Tamarugal (que abarcaba extensiones relevantes en las áreas de Curaña, Iluga, Las Pillallas, La Tirana y La Soledad, tal como lo señalan Ricardo Couyoumdjian y Horacio Larraín al analizar el mapa de Antonio O'Brien de $1765^{22}$ ) comenzó a ser parte de una dinámica extractiva asociada a la minería de la plata, rasgo que mediatizó la relación con el frágil ecosistema circundante. En efecto, la utilización diversificada y acotada de las áreas boscosas se reemplazó por una modalidad de carácter mono-explotadora en base a un uso extensivo y a mayor escala de los árboles, un cambio que se vinculó directamente con el empleo del carbón y la madera leñada de tamarugos y algarrobos como combustible para hacer funcionar los buitrones, ubicados en las cercanías del actual pueblo de La Tirana, destinados a beneficiar la plata que se extraía en los yacimientos de Huantajaya, Santa Rosa y El Carmen ${ }^{23}$, como también para cocer el caliche destinado a la fabricación de la pólvora, tal como ocurrió en los alrededores de la quebrada de Tana, al extremo norte de la Pampa del Tamarugal, donde regularmente se comenzaron a cortar molles y algarrobos para este propósito ${ }^{24}$. Prueba de ello es que la primera encomienda que involucró población indígena de Tarapacá, la de Lucas Martínez Vegazo otorgada a mediados del siglo XVI, tuvo como uno de los trabajos mejor remunerados precisamente el hacer carbón ${ }^{25}$.

A partir de estos criterios, la leña y el carbón fueron los productos económicamente más importantes; una actividad que se realizó sin mediar cultivos con propósitos de manejo controlado y mantención del bosque. En este marco, la agricultura sin riego de los canchones remarcó una aislada gestión productiva de la Pampa del Tamarugal ${ }^{26}$.

Si bien la disminución de la masa boscosa nativa durante el periodo colonial no representó un colapso ecológico, sí constituyó un preámbulo de lo que vendría más tarde con el proceso de obtención del salitre. Así lo dejaron de manifiesto tanto Francisco de Mendizábal en 1808 al plantear que el bosque de la Pampa Iluga formado por "elevados y gruesos Arboles llamados Tamarugos" se estaba "destruyendo y alejando con el continuo corte que se hace para leña y carbón" 27 , como los residentes de los Pozos de Santa Rosa, Candelaria y del Tamarugal al declarar en 1820 y 1822 respectivamente que el Pozo de El Carmen se había abandonado por la necesidad que había de trasladar el buitrón para "mayor sercania de la Leña", denotando con ello la

21 Martínez 1998, p. 111.

22 Couyoumdjian y Larraín 1975, p. 337-338.

23 Billinghurst 1886, p. 29-30; Bermúdez 1987; Carevic 1989, p. 6.

24 Carevic 1989, p. 9-10; Riso-Patrón 1903, p. 13; Villalobos 1979, p. 14.

25 Trelles 1991, p. 259-260.

26 Bermúdez 1977; Villalobos 1979, p. 95-96. Los canchones son largas y estrechas excavaciones que, después de haber sacado la dura costra salitrosa de la superficie, tienen una profundidad suficiente para capturar la capa húmeda generada por las corrientes freáticas y así posibilitar el cultivo sin riego.

27 Informe de D. Francisco Javier de Mendizábal, sobre la imposibilidad de dar agua al mineral de Guantajaya, remitido al Virrey del Perú, con carta N²56 de septiembre de 1808. En: Hidalgo 1985, p. 210. 


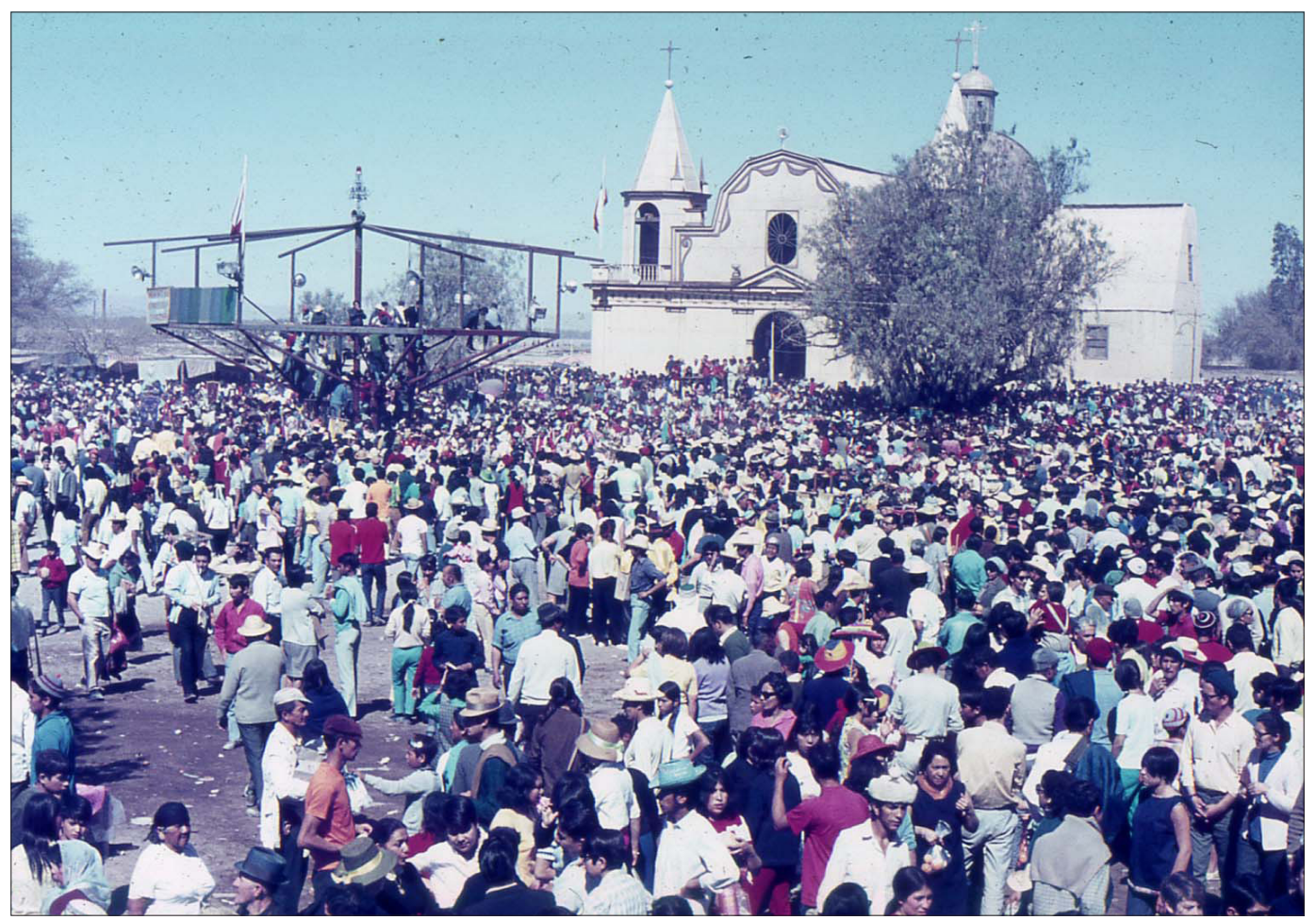

Imagen 3. Pueblo de La Tirana durante la fiesta religiosa de la Virgen del Carmen.

Fuente: Archivo Personal. Foto tomada por K. Von Buch el 16 de julio de 1970.

depredación del entorno inmediato a las instalaciones destinadas a refinar la plata de Huantajaya ${ }^{28}$.

\section{La industria salitrera, el problema de la deforestación y los proyectos de manejo del bosque \\ El periodo peruano}

El inicio del ciclo salitrero durante la primera mitad del siglo XIX ${ }^{29}$, describió la explotación más intensiva del bosque de tamarugos y algarrobos. El procedimiento de las paradas, utilizado a partir de la década de 1830 para obtener el salitre, técnica que consistió en inmensas ollas de hierro calentadas con leña, provocó una tala indiscriminada que hizo colapsar la formación boscosa del área circundante al pueblo de La Tirana y Canchones, como de la zona más al sur comprendida entre Cerro Gordo y Guatacondo $^{30}$. Como lo señala Guillermo Billinghurst, la desaparición de grandes áreas

28 Archivo del Arzobispado de Arequipa, legajo 3, Vicaría de Tarapacá, San Lorenzo de Tarapacá, Información que produce Don Luis de Arias, sobre instalación de una capilla en los Pozos de la Pampa nombrada el Tamarugal en el Partido de San Lorenzo de Tarapacá, Pozo del Tamarugal 14/8/1820, Pozo de Santa Rosa 29/10/1820, Pozo de la Candelaria 3/2/1822, s/f.

29 A diferencia de la etapa transcurrida entre la segunda mitad del siglo XVIII y primeras dos décadas del XIX, donde la extracción de salitre estuvo vinculada a la fabricación de la pólvora con un mercado consumidor interno muy restringido, el ciclo que se inició en la década de 1830 se caracterizó por una producción a escala mayor impulsada por un mercado mundial que lo requirió como fertilizante.

30 Bermúdez 1977, p. 417; Carevic 1989, p. 6; Zolezzi 1993, p. 6. 
de tamarugo y algarrobo fue resultado de las faenas industriales decimonónicas que encontraron en el bosque de la Pampa del Tamarugal una materia prima barata, de fácil acceso y relativamente abundante ${ }^{31}$.

Pero no solo la minería del salitre fue causante de este desastre ecológico, también influyó la continuidad operativa de los buitrones del pueblo de La Tirana para refinar la plata de las minas de Huantajaya y Santa Rosa, y la quema descontrolada de árboles en los alrededores de la Huayca y La Soledad para obtener carbón, una práctica que involucró tanto a las especies vivas como las muertas y que se tradujo en un comercio lucrativo que alcanzó tanto a las oficinas salitreras como a los puertos guaneros ubicados al sur de Iquique ${ }^{32}$, además de importantes réditos a la administración fiscal, tal como quedó demostrado a comienzos de 1870 cuando a través de la prensa de Iquique se apoyó la petición de la municipalidad para que con los tributos recaudados por contribución de leña y carbón se financiara la construcción y habilitación de una escuela elemental ${ }^{33 .}$.

Ante la evidencia del deterioro del bosque nativo, a fines de 1829 en el más importante periódico arequipeño de la época se señaló que era oportuno y necesario que en todo el departamento, especialmente en la Pampa del Tamarugal, "se emprendiese una plantación de bosques de otras especies de árboles análogas á nuestro clima" y que se establecieran "molinos de viento para la molienda de los metales" como mitigación ${ }^{34}$. En los mismos términos, a inicios de 1846 en un diario tacneño se puso de manifiesto el interés del gobierno por remediar esta situación mediante un proyecto de irrigación de una porción importante de esta zona trasvasando aguas precordilleranas ${ }^{35}$; una idea que tuvo su ratificación en la prensa limeña en agosto de 1848 al informarse que "separándose de la inmensa superficie de dicha pampa una costra que se denomina caliche aparece una tierra húmeda de calidad" a la que se le puede sacar "incalculables ventajas para la agricultura abriendo pozos" que capturen el agua subterránea ${ }^{36}$.

El impacto ecológico que comenzó a evidenciarse por el proceder asociado a la minería salitrera, a la extracción argentífera y al consumo de carbón por parte de la creciente población que comenzaba a habitar la provincia de Tarapacá, fue tal respecto al retroceso de las hectáreas de los árboles nativos que en 1851 William Bollaert, explorador y químico inglés que vivió varios años en la zona y que realizó la primera expedición encargada por la administración peruana en 1827-1828, manifestó que la explotación de los montes tarapaqueños para generar combustible destinado a las minas era insostenible ya que el "crecimiento de los árboles no [era]

31 Billinghurst 1886, p. 34.

32 Bermúdez 1977, p. 409; Zolezzi 1993, p. 7.

33 El Mercurio de Iquique, Iquique 6/3/1870, p. 3.

34 El Republicano, Arequipa 3/10/1829, p. 5; El Republicano, Arequipa 7/12/1829, p. 3. La preocupación de la prensa arequipeña tiene que ver con que hasta 1837 la provincia de Tarapacá formó parte del Departamento de Arequipa.

35 El Moqueguano, Tacna 7/1/1846, p. 1. El interés de la prensa tacneña se sustenta en el hecho de que la provincia de Tarapacá desde 1837 pasó a ser una sección administrativa del departamento de Moquegua cuya capital se estableció en Tacna.

36 El Comercio, Lima 2/8/1849, p. 2. 
proporcional al ritmo de consumo"37. En los mismos términos el naturalista italiano Antonio Raimondi, que visitó Tarapacá a fines de 1853 por mandato del presidente Rufino Echenique a efecto de tener datos más precisos del potencial tanto de la riqueza salitrera como del bórax, señaló que era "muy delicioso el pasar a la sombra de estos árboles muy verdes después de tanta aridez" y por ello era una "lástima muy grande" que los corten para "hacer leña" ya que "desaparecerán para dar luego a un desierto" 38 (ver imagen 4).

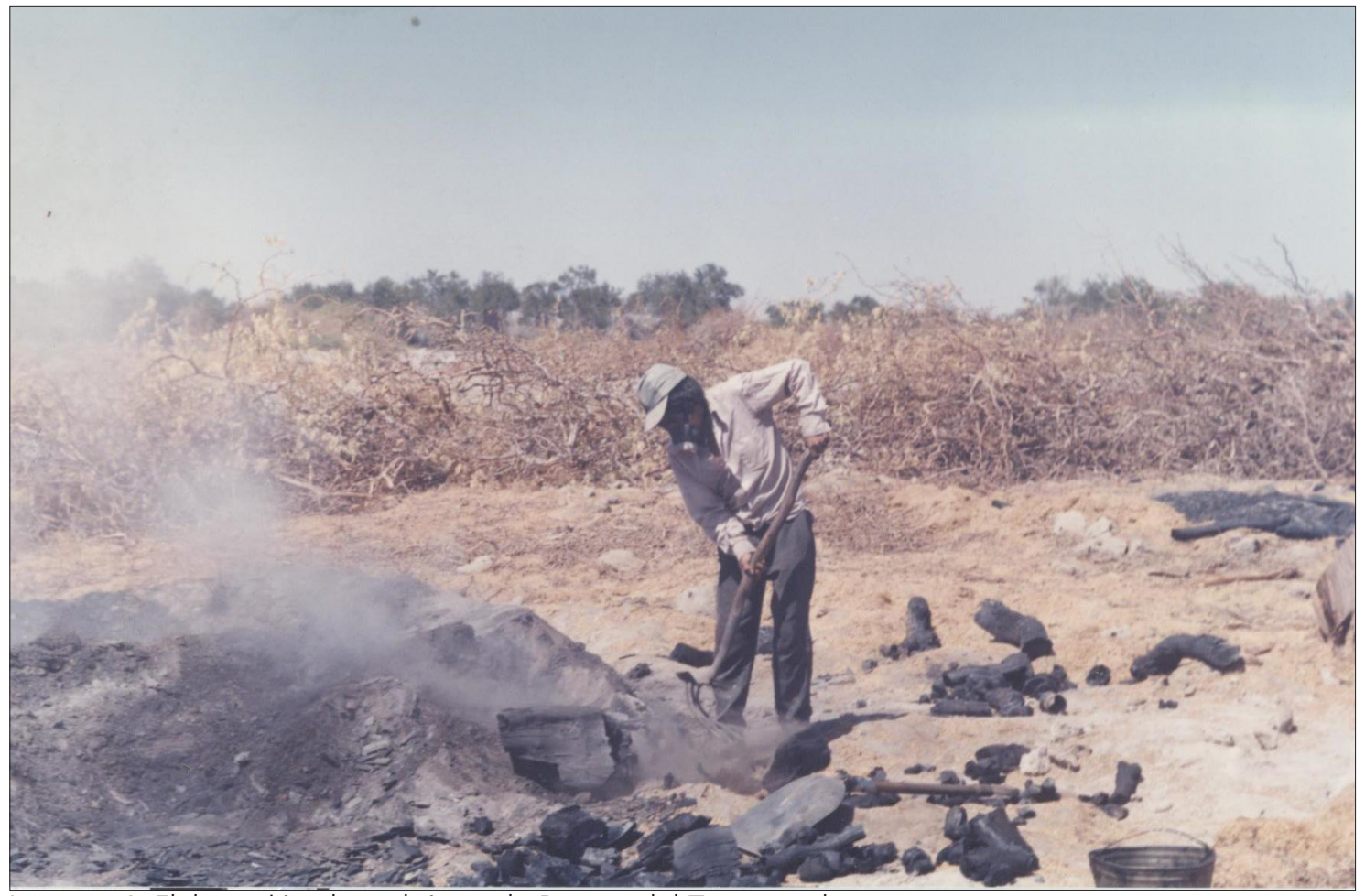

Imagen 4. Elaboración de carbón en la Pampa del Tamarugal.

Fuente: Archivo Fotográfico CONAF Región de Tarapacá, Iquique.

Ante una situación tan preocupante, no tardaron en emerger un conjunto de requerimientos por revertir o paliar el deterioro del bosque del desierto y su potencial económico asociado a lo agrícola. Así, en octubre de 1856, en el periódico más influyente de Lima, se afirmó que la "hermosa Pampa del Tamarugal" era una riqueza obligatoria de recuperar de su condición de "industria muerta" para el bienestar de todo el Perú ${ }^{39}$. En correlato, durante el mes de abril de 1861, el editor del único medio de prensa iquiqueño de la época reclamó con vehemencia que el "lamentable atraso" de la provincia tarapaqueña tenía por consecuencia más evidente el deterioro paulatino de los "valiosos establecimientos y ricos terrenos salitrales" como la "inutilización de la riqueza de la pampa del Tamarugal", y que por lo mismo era "cosa extraña" de que "todo el mundo parece resignarse a él, cuál si fuera sentencia escrita en el libro del destino"

37 Bollaert 1851, p. 112.

38 Raimondi 2017 [1853], p. 137 [21].

39 El Comercio, Lima 27/10/1856, p. 6.

40 El Mercurio de Tarapacá, Iquique 8/4/1861, p. 1. 
epítetos que reiteró en la edición del mes de octubre a propósito de la visita del ministro de gobierno Juan Oviedo. En esta ocasión, el editor fue enfático en manifestar que no le cabía duda que Oviedo, a su regreso a Lima, no dejaría de ilustrar al gobierno "cuan deplorable es la situación de una provincia digna de mejor suerte", especialmente de su "agonizante agricultura" practicada en el Tamarugal y que tenía por "único éxito relativo [los esfuerzos de los] agricultores de La Tirana llevados a cabo en orfandad del apoyo gubernamental"41.

En base a estas y otras peticiones, el 5 de diciembre de 1856 la Convención Nacional presentó, acogiendo la moción del diputado Juan B. Zavala, un proyecto para impulsar la irrigación en la provincia de Tarapacá mediante la formación de una Junta de Irrigación que administrara e impulsara obras e iniciativas a financiar mediante el cobro de un impuesto a la exportación del bórax ${ }^{42}$, y en 1863 el gobierno peruano encargó al ingeniero M.J. Church una evaluación de factibilidad para la irrigación de la Pampa del Tamarugal ${ }^{43}$, iniciativas que tuvieron como antecedentes preliminares los proyectos coloniales de Antonio O'Brien de 1765 y de Francisco Javier Mendizábal de $1807^{44}$, la legislación borbónica de 1748 que, mediante la Ordenanza para la Conservación y Aumento de los Montes de Marina y la Real Ordenanza para el Aumento y Conservación de Montes y Plantíos, obligaba a plantar tres árboles por cada uno que fuera talado ${ }^{45}$ y las propuestas del ingeniero estadounidense John H. Blake de 1843 y la del ingeniero chileno Francisco Puelma de $1855^{46}$.

La propuesta de Church y la posibilidad de capturar aguas a gran escala con fines de irrigación, generó una creciente expectativa al interior de la opinión pública tarapaqueña en los años que le siguieron. Por ejemplo, en El Mercurio de Tarapacá de octubre de 1867, se planteó que las "represas en la quebrada de Tarapacá para depositar las aguas temporales" eran "obras importantes que [debian] estudiarse por una comisión de ingenieros" ya que con ellas se podía "regarse la pampa Iluga"47, sección de la Pampa del Tamarugal aledaña al pueblo de Huara. En abril de 1869, en tanto,

41 El Mercurio de Tarapacá, Iquique 25/10/1861, p. 1.

42 Informe de la Comisión de Agricultura sobre el Proyecto de Irrigación de la Provincia de Tarapacá presentado a la Convención Nacional 1857, p. 3-10. Este proyecto de ley, además de consignar el financiamiento mediante el impuesto al bórax y la constitución de una Junta de Irrigación contempló, por una parte, la otorgación de un privilegio de exclusividad por 20 años a las empresas o individuos que construyeran pozos artesianos en la Pampa del Tamarugal y, por otra, la declaración de propiedad municipal de los terrenos baldíos comprendidos en sus respectivas jurisdicciones, pudiendo concesionarlos para aumentar sus rentas a condición de que se cultivaran y reforestaran en un plazo máximo de cinco años.

43 Billinghurst 1886, p. 104; Billinghurst 1893, p. 88-89; Van Kessel 1985, p. 145.

44 Antonio O'Brien sugirió canalizar las aguas de las lagunas de Lirima hasta en nacimiento de la quebrada de Tarapacá y represarlas en este lugar para su distribución hacia la Pampa del Tamarugal. Mendizábal, en cambio, propuso la construcción tanto de ingenios movidos por viento como norias en la Pampa del Tamarugal para, de este modo, sacar agua suficiente destinada al cultivo, desechando por cuestiones técnicas la opción de trasvasar recursos hídricos desde Lirima y Sibaya. Ver: Hidalgo 1985, p. 186-193.

45 Simón Ruíz 2011, p. 196-197.

46 Blake 1843, p. 1-12; Puelma 1855, p. 665-673.

47 El Mercurio de Tarapacá, Iquique 19/10/1867, p. 3; El Comercio, Lima 25/10/1867, p. 3. 
el mismo medio de prensa resaltó que el designado prefecto de la nueva Provincia Litoral de Tarapacá, el limeño Miguel Valle-Riestra, había regresado muy entusiasmado de su viaje al interior al constatar la "vasta riqueza agrícola que presentan los canchones en la pampa del Tamarugal, en los que sin riego alguno producen hermosa alfalfa, trigo, cebada, zapallos, y cuanto se siembra"48. Finalmente, como corolario de esta tendencia, a inicios de febrero de 1870, en El Mercurio de Iquique, se anunció que el prefecto Valle-Riestra le había pedido al ministro de gobierno que a "esta sección de la República" no la favorecieran ni con "vías férreas, ni suntuosos monumentos de crecido valor", sino "únicamente con la irrigación de la pampa del Tamarugal y el aumento de las aguas de Tarapacá" 49 y, por otra, que el "interés de los congresos y de los gobiernos que han decretado el reconocimiento y estudios convenientes" era directa consecuencia de la "fertilidad de los terrenos de esta planicie [del Tamarugal] que produce toda clase de frutos con poco trabajo preparatorio del hombre" 50 .

A partir de esta corriente de opinión pública, avalada por la decidida postura de Valle-Riestra a favor de impulsar obras de irrigación para la Pampa del Tamarugal, se generó un incremento sostenido de solicitudes de terrenos ubicados en esta área para emprendimientos agrícolas, entre ellos los de Baltazar Gallegos que denunció en junio de 1869 media legua cuadrada ${ }^{51}$, misma cantidad que pidió Juan E. Albarracín un mes más tarde y que volvió a reiterar en otros dos denuncios de agosto y octubre $^{52}$, a la par de la petición de María Barreda y su hermana Manuela cursada igualmente en agosto de 1869 de diez topos de terreno en el sector de los Canchones $^{53}$ (ver imagen 5). También la formación en la localidad de San Lorenzo de Tarapacá de una comisión compuesta por Joaquín del Carpio (gobernador del distrito), Pedro José Mercado (miembro del concejo municipal), Manuel O. Vega, José Quiroga, Esteban Vernal y Manuel Capetillo destinada al "reconocimiento para el desarrollo de obras hidráulicas en el valle de Tarapacá para fomento agricola"; comisión que, entre otras opciones, consideró "fertilizar las hermosas pampas de Iluga en la desembocadura de la del Tamarugal" en base a un presupuesto estimado en 20.000 soles $^{54}$.

Llegó a ser tan intenso el interés por contar con terrenos en la Pampa del Tamarugal ante la posibilidad de contar con grandes volúmenes de agua trasvasadas desde la cordillera, que un personaje tan ilustre como Guillermo Billinghurst denunció un terreno en Cuminalla a inicios de $1870^{55}$. Claro que esta última solicitud tuvo en

48 El Mercurio de Tarapacá, Iquique 20/4/1869, p. 3.

49 El Mercurio de Iquique, Iquique 5/2/1870, p. 3.

50 El Mercurio de Iquique, Iquique 5/2/1870, p. 1.

51 El Mercurio de Tarapacá, Iquique 19/6/1869, p. 4.

52 El Mercurio de Tarapacá, Iquique 8/7/1869, p. 2; El Mercurio de Tarapacá, Iquique 20/8/1869, p. 4; El Mercurio de Tarapacá, Iquique 20/10/1869, p. 4.

53 El Mercurio de Tarapacá, Iquique 20/8/1869, p. 4.

54 El Eco de Tarapacá, ${ }^{\circ} 13$, Año 1, Tarapacá 28/12/1869, p. 2. Anexado en: Archivo General de la Nación del Perú, Expedientes Oficiales del Ministerio de Hacienda (en adelante AGNP-MH), legajo OL-503, pieza 3206, caja 937, Informe del prefecto sobre obras hidráulicas para el valle de Tarapacá, Iquique 1869 , s/f.

55 El Mercurio de Iquique, Iquique 5/2/1870, p. 4. Sobre la trayectoria de Guillermo Billinghurst 


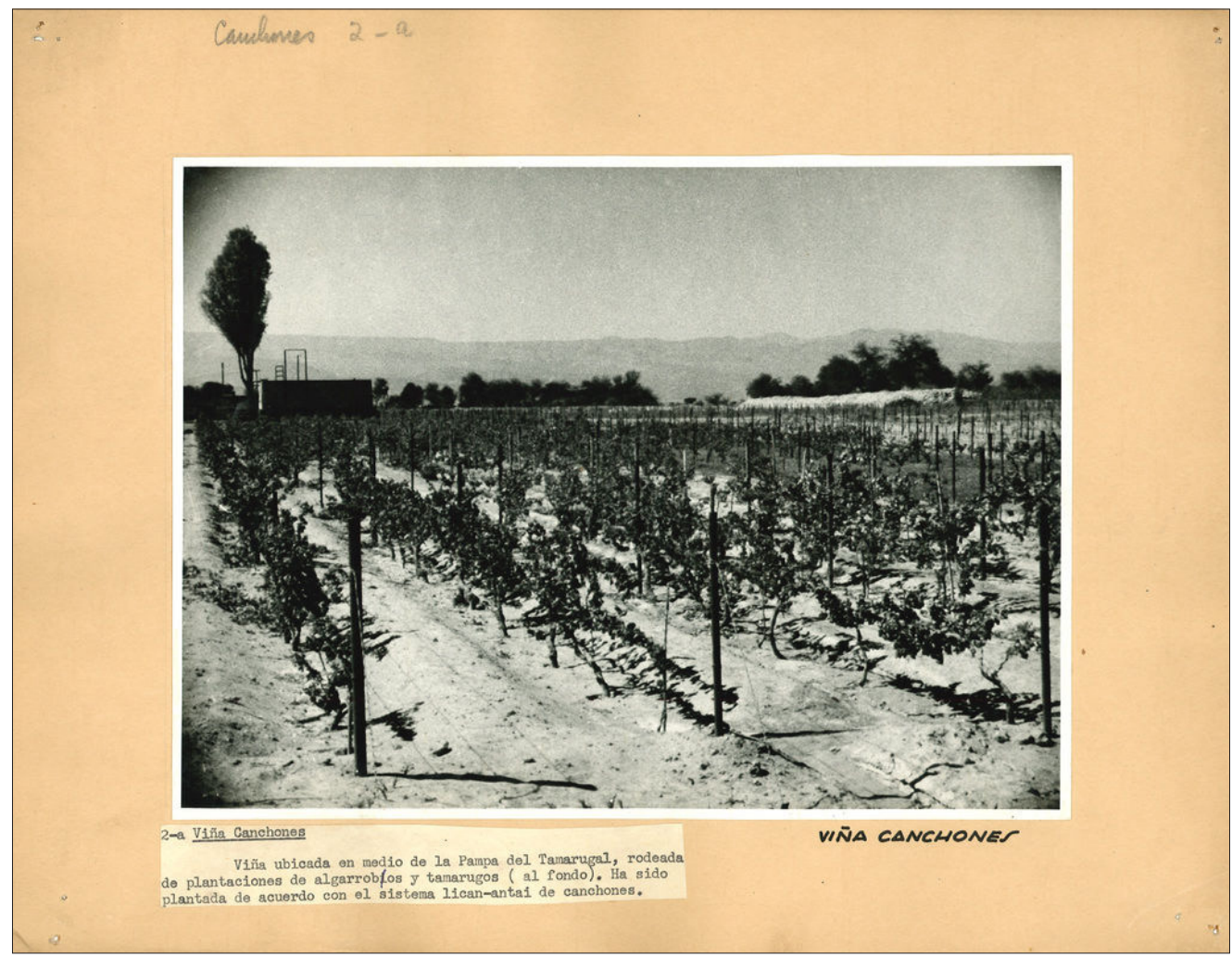

Imagen 5. Plantación de viña en el sector de Canchones de la Pampa del Tamarugal. Fuente: Coleccion Documental Enciclopedia Chilena, ECH3343. En: www.bcn.cl.

cuenta los decretos del ministerio de gobierno del 26 de enero y 10 de marzo de 1870 mediante el cual se encargó al ingeniero de estado Eduardo Habich realizar estudios preliminares para dotar de acuíferos superficiales a esta cuenca endorreica tomando en consideración de que las "obras de irrigación" son las que "más poderosamente contribuyen al desarrollo de la agricultura"56. Decisión gubernamental a la que se le agregó la propuesta de actores locales de que se habilitara un Banco Hipotecario en el puerto de Iquique por la "mayor utilidad" que prestaría tanto al incremento de la minería como al desarrollo "en grande escala de la industria agricola en el Tamarugal" $^{\prime \prime}$, y la iniciativa del empresario Carlos Freraut de regalarle a varios canchoneros 22 eucaliptus Camaldulensis, 5 molles Schinus latifolius y 2 acacias Heterophylla para que "ensayaran su cultivo en el Tamarugal"58.

A pesar de todo este movimiento 59 , la comisión de Habich no se materializó, generando en la opinión pública tarapaqueña cierta desazón y, a la vez, la reactivación

ver González 2000.

56 El Mercurio de Iquique, Iquique 5/2/1870, p. 3; El Mercurio de Iquique, Iquique 12/4/1870, p. 3.

57 El Mercurio de Iquique, Iquique 5/6/1870, p. 1.

58 El Mercurio de Iquique, Iquique 20/6/1870, p. 3.

59 El incremento que tuvieron los denuncios en la década de 1860 para acceder a terrenos con potencial de riego en la Pampa del Tamarugal, tuvo su sustento tanto en una genuina expectativa como en un ejercicio especulativo por parte de quienes vieron la posibilidad de arrendar los terrenos concesionados a un tercero en caso de que se concretaran los proyectos de riego con financiamiento estatal. A esto se le sumó el interés del fisco de generar ingresos mediante una tasa impositiva y hacer productivas tierras áridas y baldías. No obstante, su incidencia en posibles impactos ambientales 
de las demandas con una mayor vehemencia. Así, a fines de 1870, la editorial de $E l$ Mercurio de Iquique espetó que había "llegado el tiempo de que el Supremo Gobierno en cumplimiento de las diferentes disposiciones que ha dado a este respecto mande una o dos personas competentes de entre el selecto cuerpo de ingenieros con el loable fin de irrigar la [provincia]"60, requerimiento que se reiteró a inicios de 1871 argumentándose de que en "general casi todos los pueblos de la Provincia son escasos del agua precisa para su cultivo, pero el terreno que más lo necesita y con ella produciría incalculables beneficios, es la célebre pampa del Tamarugal" ${ }^{\prime 6}$.

La persistencia de esta campaña durante todo el transcurso del año 1871, llevó a que en 1872 el gobierno le solicitara al ingeniero Oton Buchwald la realización de un acabado estudio del sistema hidrológico de la Pampa del Tamarugal y su potencialidad económica agrícola ${ }^{62}$. Este estudio, a diferencia de las anteriores y parciales prospecciones encomendadas por el ejecutivo desde Lima, tuvo como resultado la primera propuesta que se conoce de manejo integral y sustentable del recurso forestal del desierto de Atacama amparado en análisis científicos. La proposición de Buchwald consignó, primero, la reforestación de toda el área de Canchones y Refresco desde La Tirana a la Huayca-Cumiñalla de norte a sur y de la línea La Calera-Pica-Puquio Núñez a los bordes de los salares de Bellavista y Pintados de este a oeste. Segundo, la utilización privilegiada del algarrobo por sus cualidades como pasto, leña, alimento para ganado y consumo doméstico de su fruto. Tercero, la plantación de 10.000 a 12.000 árboles en una superficie de 10 hectáreas hasta llegar a un promedio de 100.000 unidades cada un kilómetro. Cuarto, la administración del área reforestada por un guardabosque ${ }^{63}$.

Para concretar esta iniciativa, el gobierno peruano durante la presidencia de Manuel Pardo promulgó el 13 de mayo de 1873 un decreto que, por una parte, legalizó la vigilancia de las áreas boscosas y, por otra, penalizó su destrucción ${ }^{64}$, además de formalizar la creación de la Comisión Agrícola Pampa del Tamarugal, una instancia que tuvo por meta principal la recuperación de la masa de árboles de copa alta con capacidad de atracción de la humedad atmosférica en zonas despobladas de vegetación e incentivar la agricultura ${ }^{65}$. Puntualmente, mediante este decreto se autorizó al prefecto de Tarapacá para que concediera a quienes lo solicitaran hasta veinte hectáreas para ser cultivas con sementeras y árboles con un plazo de vencimiento de inicio de las plantaciones de un año para la mitad y de tres para la totalidad del terreno entregado. Cumplido con lo anterior, la concesión se extendería por 10 años para las sementaras y de 20 para los árboles, además de consignar el pago de un canon anual de 10 soles por hectárea a partir del cuarto año para las sementeras y del sexto para los árboles ${ }^{66}$.

positivos y negativos al ecosistema boscoso fue nulo al no concretarse ninguna de las iniciativas de irrigación.

60 El Mercurio de Iquique, Iquique 12/12/1870, p. 1.

61 El Mercurio de Iquique, Iquique 4/1/1871, p. 2.

62 Billinghurst 1886, p. 104; Bermúdez 1977, p. 415.

63 Billinghurst 1886, p. 105; Billinghurst 1887, p. 152-153; Bermúdez 1977, p. 415-416.

64 Billinghurst 1893, p. 166.

65 Bermúdez 1977, p. 416.

66 El Mercurio de Iquique, Iquique 24/5/1873, p. 2. 


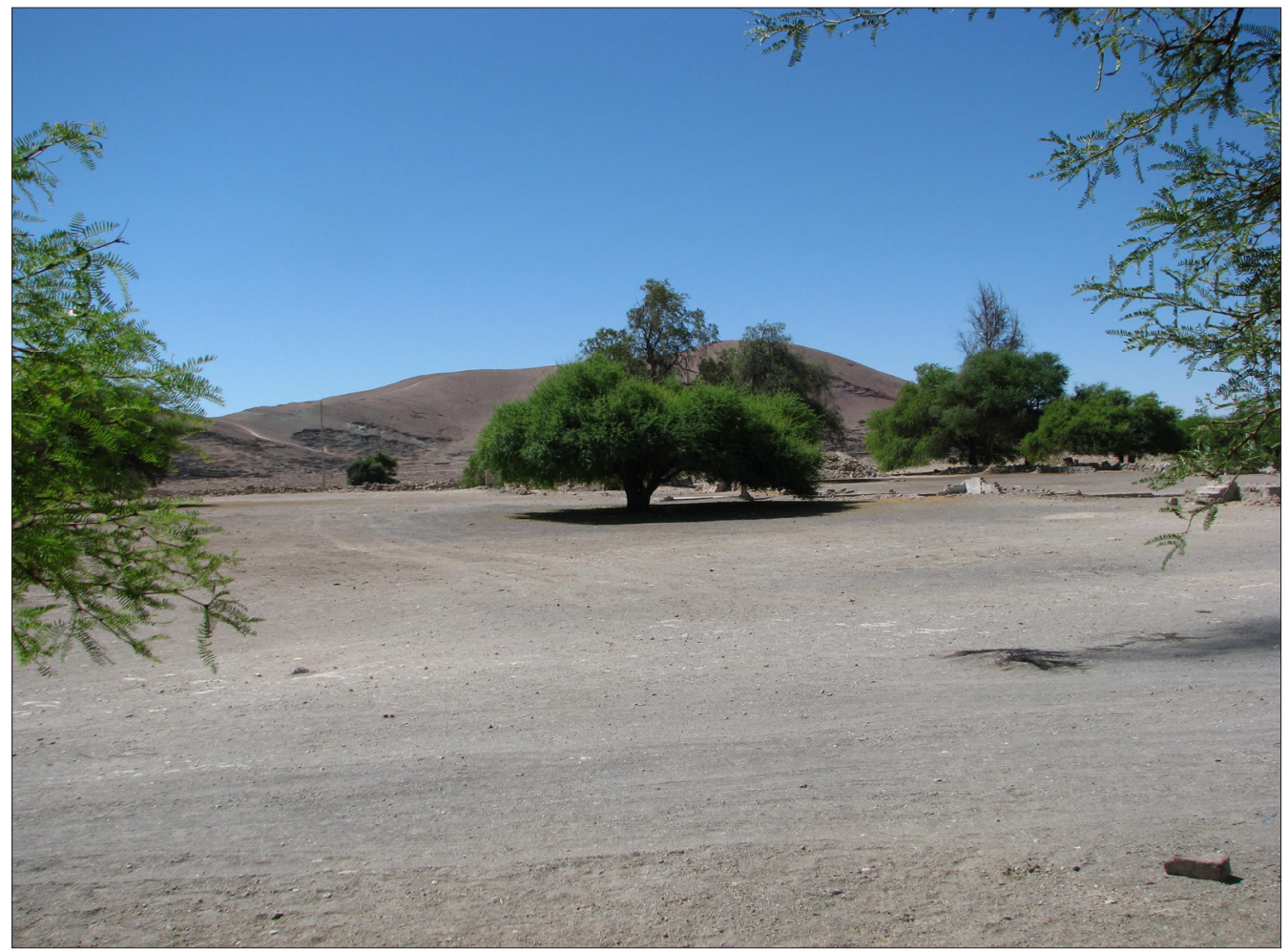

Imagen 6. Imagen actual del bosque de la Pampa del Tamarugal.

Fuente: Archivo fotográfico de Sergio González.

Debido a numerosas críticas sobre los plazos y condiciones, el decreto se modificó el 8 de octubre de 1873, estableciéndose esta vez el tiempo máximo para cumplir con el inicio de los cultivos de dos años para la mitad y de cuatro para el total de las hectáreas concesionadas ${ }^{67}$.

No obstante, las intenciones de esta medida gubernativa, los logros no fueron sustanciales. Contra su efectividad actuó desde un comienzo la recurrente falta de recursos tanto para implementar una red de vigilancia como para sostener los requerimientos de funcionamiento de la Comisión Agrícola, tal como lo recalcó su encargado, Miguel Valle-Riestra, al solicitar a fines de noviembre de 1873 una asignación adicional de 3.000 soles para reforzar la operatividad ${ }^{68}$, como en un oficio que le dirigió el 20 de diciembre del mismo año al ministro de Hacienda indicándole que desde que se hizo cargo de la repartición, algo más de seis meses atrás, había:

Tenido que luchar con inconvenientes casi insuperables provenientes de las dificultades que la caja fiscal de aquella provincia ha tenido para cubrir los gastos más urgentes de la comisión, pues no estando considerado en el presupuesto de dicha caja los gastos ya mencionados, se ha visto obligada a recurrir siempre a pedidos extraordinarios hechos a la Aduana principal de Iquique, cuya oficina, a su vez, sin instrucciones especiales ha tomado sobre sí la responsabilidad de cubrir estos gastos, aunque ocasionando continuamente, contra su voluntad, perjudiciales retardos en las operaciones de la comisión ${ }^{69}$.

67 El Mercurio de Iquique, Iquique 14/10/1873, p. 3.

68 AGNP-MH, legajo OL-514, pieza 2036, caja 97, Iquique 12/11/1873, s/f.

69 AGNP-MH, legajo OL-516, documento 20, Comisión Agrícola del Tamarugal, Lima 20/12/1873, s/f. 
La falta de recursos económicos no solo tuvo que ver con un tema estricto de gestión, sino con una barrera estructural casi insalvable a debida cuenta que el gobierno de Manuel Pardo recibió al país con una crisis financiera de proporciones ${ }^{70}$, lo que dificultó desde un comienzo tanto la entrega a tiempo de los aportes regulares comprometidos desde el nivel central como, a medida que pasaron los meses, la posibilidad de obtener montos adicionales en Lima como en Iquique. A este inconveniente se le sumó, a poco andar la Comisión Agrícola del Tamarugal, una férrea oposición a Valle-Riestra desde ciertos sectores influyentes de la zona a debida cuenta de una predisposición difícil de subsanar que provenía desde que en 1868 asumió, por disposición del presidente José Balta, el cargo de primer prefecto de la recién creada Provincia Litoral no siendo oriundo de la zona, pero además por tomar la decisión de ejercer su rol de máxima autoridad política radicándose en Iquique y no en San Lorenzo de Tarapacá, a pesar que esta última localidad todavía era la capital de la provincia¹. Por tanto, Valle-Riestra se encontró con una doble dificultad para conseguir aportes monetarios que le permitieran poner en marcha la Comisión. Por una parte, no le era posible obtenerlo desde el gobierno central por la crisis económica que atravesaba el país al declinar el ciclo guanero. Por otra, tampoco desde el gobierno provincial al no ser bien acogido por quienes tomaban decisiones tanto en Iquique (el centro financiero-mercantil) como en San Lorenzo de Tarapacá (la capital político-administrativa).

Por si fuera poco, en un momento clave respecto a la constitución operativa de la Comisión Agrícola, Valle-Riestra debió enfrentar adicionalmente un creciente rechazo hacia esta iniciativa de protección del bosque del Tamarugal por ser vista como una movida subrepticia del gobierno de Pardo para contener la férrea oposición a su proyecto del estanco salitrero, lo que desde un inicio fue asumido transversalmente por los tarapaqueños como un perjuicio para los intereses de la zona y un indicio más del poco interés del gobierno central por esta parte del territorio nacional ${ }^{72}$. En efecto, el monopolio del comercio del salitre se convirtió en una prioridad del gobierno civilista para enfrentar la penuria fiscal que experimentaba el Perú, generando con ello la posibilidad de reemplazar la renta guanera, en franca declinación, por la renta salitrera, una industria que había entrado en una decida expansión al punto de constituirse en 1872 la mayor exportación del país ${ }^{73}$. El punto en cuestión es que la ley del estanco,

70 Basadre 2014, p. 150-185; Flores 2000, p. 39-44; Flores 2018, p. 64-65.

71 La prensa iquiqueña de la época (1867-1868), deja en evidencia que en vastos sectores influyentes de Tarapacá hubo una expectativa muy alta que el presidente Balta nombrara como primer prefecto de la creada Provincia Litoral a un genuino tarapaqueño, el cuál tendría más que ningún otro el entendimiento, interés y capacidad para llevar a cabo los anhelos de progreso económico, como la capacidad de frenar el abandono en que se encontraba por parte del gobierno central. Como esto no sucedió, la resistencia a Valle-Riestra fue creciendo a medida que transcurrió su desempeñó como prefecto, críticas que terminaron cuando dejó el cargo los primeros días de 1870. De esta manera, cuando regresó a la provincia para asumir la dirección de la Comisión Agrícola del Tamarugal dos años más tarde, inmediatamente emergieron sentimientos en su contra que habían estado contenidos desde que dejó la prefectura, lo que se traspasó de inmediato hacia un rechazo a esta Comisión y sus objetivos de preservar el bosque.

72 González 2012; Castro 2017.

73 Bonilla 1980; Flores 2018, p. 66-67; Mathew 2009; Mc Evoy 2007, p. 247. 
del 18 de enero de 1873, fue considerada por los tarapaqueños, especialmente los empresarios salitreros, como la materialización de un monopolio en beneficio de la oligarquía limeña imposible de aceptar toda vez que esto implicaba que les arrebataran, sin mayor justificación, años de arduo y sacrificado trabajo por sostener una actividad sin apoyo gubernamental ${ }^{74}$. En consecuencia, ante un Valle-Riestra cuestionado y una Comisión rechazada a priori por ser vista como un paliativo al interés del gobierno central y la oligarquía limeña por hacerse de la renta salitrera sacrificando el destino de los tarapaqueños, hizo inviable el sostener la iniciativa de proteger y recuperar el bosque del Tamarugal mediante la gestión de un área protegida.

Precisamente esto delató el editor de El Mercurio de Iquique, en sus ediciones de mediados de 1873, como Modesto Basadre en 1884. El primero, al cuestionar enfáticamente los alcances del comodato y sus fundamentos:

¿Qué género de concesión es aquella que se hace solo por diez años, y que impone la condición de que se pague un canon al Estado al hacerse productivo ese terreno eriazo que en el día posee ningún valor? [Evidentemente] concesiones liberales, que son tan frecuentes en el día [y que] destruyen para siempre la esperanza de vernos un día independientes, ya que un capítulo de mezquindad anima al gobierno a reducir a la condición de feudos a nuestros labradores del Tamarugal ${ }^{75}$.

Además de denunciar que lo único que podía explicar lo anterior era que el gobierno persistía "en una idea que, por más que luchemos contra su calificación, ha de llevar el nombre de la insensatez"76; razón por lo cual no era capaz de darse cuenta de que la "comisión nombrada no [podía] emplear estos requisitos" ni tampoco acotar el "objeto que se desea en el cultivo de los artículos de más apremiante necesidad para el consumo de la provincia" a consideración de preguntarse inevitablemente "¿Qué importa el cultivo de los árboles, cuyo producto y valor perspectivo se cuenta por los años, ante la imperiosa demanda por pastos?"7 . El segundo, en tanto, al señalar que este plan fue "una de las locuras de la Administración Pardo"rs. De este modo, se hizo explícito que la resistencia a la Comisión del Agrícola del Tamarugal tuvo de forma predominante un fuerte componente político toda vez que las trabas, más que tomar en cuenta consideraciones alternativas respecto al manejo de los recursos forestales y el potencial agrícola, tuvieron como propósito sustancial el obstruir el gobierno civilista.

Bajo estos términos, la única posibilidad de que esta iniciativa siguiera funcionando fue que primaran los criterios económicos de corto plazo por sobre los beneficios medioambientales de mayor alcance, sobre todo para mitigar la idea extendida entre los rivales al gobierno de que la Comisión era más bien un instrumento para afianzar las pretensiones monopólicas del estado controlado por los civilistas que una herramienta de desarrollo para la provincia. Entonces, como era de esperar, tanto los inconvenientes operativos como la férrea obstrucción de los sectores locales

74 González 2012, p. 105-110; Castro 2017, p. 50-51.

75 El Mercurio de Iquique, Iquique 1/6/1873, p. 2.

76 El Mercurio de Iquique, Iquique 7/6/1873, p. 2.

77 El Mercurio de Iquique, Iquique 14/6/1873, p. 2.

78 Basadre 1884, p. 183. 
vinculados al empresariado salitrero terminaron por provocar que, al poco tiempo, se desvirtuara el propósito inicial de esta Comisión Agrícola al derivar sus esfuerzos hacia el fomento del cultivo de la alfalfa, una planta de valor comercial inmediato al estar destinada al consumo de los animales de carga utilizados en las faenas extractivas del salitre.

Así, esta Comisión dejó de ser funcional a la recuperación del bosque nativo de la Pampa del Tamarugal, decretándose su disolución a mediados de 1875 para beneplácito de sus detractores ${ }^{79}$, los mismos que llegaron a decir un año más tarde que era necesario y obligatorio dejar constancia "para toda época" del "escandaloso derroche que hizo el gobierno de don Manuel Pardo en las pampas del Tamarugal"80, aduciendo con ello tanto al sueldo que le fue asignado a Valle-Riestra como a su equivocada política del estanco y monopolio del salitre y la idea de compensar a la provincia con la activación de planes de riego y reforestación. Lo curioso de estos cuestionamientos es que en forma paralela un grupo de agricultores del valle de Tarapacá con intereses salitreros, como Antonio Cevallos, Fermín Vernal, Félix Olcay, Eduardo Caucoto, Manuel Vernal, Marcelino Luza, Andrés Loayza, Mariano Perea, entre otros, estaban creando una Sociedad Anónima destinada a implementar un proyecto de irrigación, tanto de la quebrada como de una área aledaña a la Pampa del Tamarugal, desaguando aguas cordilleranas ${ }^{81}$, poniendo de este modo en entredicho los argumentos de los salitreros para deslegitimar lo que había sido la Comisión Agrícola.

A pesar del fracaso institucional de la iniciativa del gobierno civilista de salvaguardar el bosque de la Pampa del Tamarugal mediante un manejo integral incorporando, de manera complementaria, la agricultura con y sin riego, para fines de la década de 1870 el monte de tamarugos y algarrobos aún eran parte del paisaje tarapaqueño producto de lo que se alcanzó a realizar en el ámbito de la reforestación en el trascurso de los años 1873-1875, tal como lo describió el expedicionario chileno Alejandro Bertrand al señalar que para quien visita por primera vez el desierto tarapaqueño le "sorprende ver en el horizonte árboles", entre ellos "tamarugos, corpulentos espinos y algarrobos [que] se conservan en toda lozanía" en la zona de Canchones, en los alrededores del pueblo de La Tirana al sur y en el camino que parte desde el pueblo salitrero de La Noria ${ }^{82}$, áreas donde precisamente intervino la Comisión Agrícola del Tamarugal en su corta existencia.

\section{El periodo chileno}

El dominio chileno de la provincia de Tarapacá, desde comienzos de la década de 1880, no solo trajo consigo un cambio de administración sino también la ejecución de una política rentista que intensificó la explotación del salitre a niveles tales que la econo-

79 El Comercio, Iquique 4/7/1875, p. 2.

80 El Comercio, Iquique 16/9/1876, p. 2.

81 Archivo Nacional de Chile, Fondo Notarial de Tarapacá, volumen 14, protocolo 1876, minuta 79, San Lorenzo de Tarapacá 20/6/1876, fol.73-77; Archivo Nacional de Chile, Fondo Notarial de Iquique, volumen 18, registro 62, documento 22, Iquique 21/6/1876, fol. 27v-28.

82 Bertrand 1879, p. 4-5. 
mía local, como la del país, pasó a depender exclusivamente de esta actividad. En el ámbito regional, este proceso provocó un nuevo e intenso debate público en donde se explicitaron interesantes planteamientos referidos a la posibilidad cierta de desarrollar una industria agrícola en la Pampa del Tamarugal a partir de irrigaciones a gran escala en articulación con un proyecto político de desarrollo regional ${ }^{83}$. En este escenario, la preocupación por los recursos forestales por parte de distintos sectores de la sociedad tarapaqueña comenzó a girar en torno al interés por adscribirlos a una estrategia económica integral de largo plazo, cuestión que redundó, por una parte, en una sensible inquietud por la depredación que había padecido por largo tiempo el bosque y, por otra, en la aceptación pública en diversos sectores de la provincia de que era posible un manejo con claros parámetros de preservación no contradictorios con un uso económico racional.

La plantación de tamarugos y algarrobos por parte de privados fue incentivada desde un comienzo tanto por los jefes políticos como por los intendentes ${ }^{84}$, quienes vieron en estas acciones un modo de recuperar las hectáreas perdidas en las décadas anteriores ${ }^{85}$. Por ejemplo, a finales de 1886 se le otorgó en concesión a Juan Dassori,

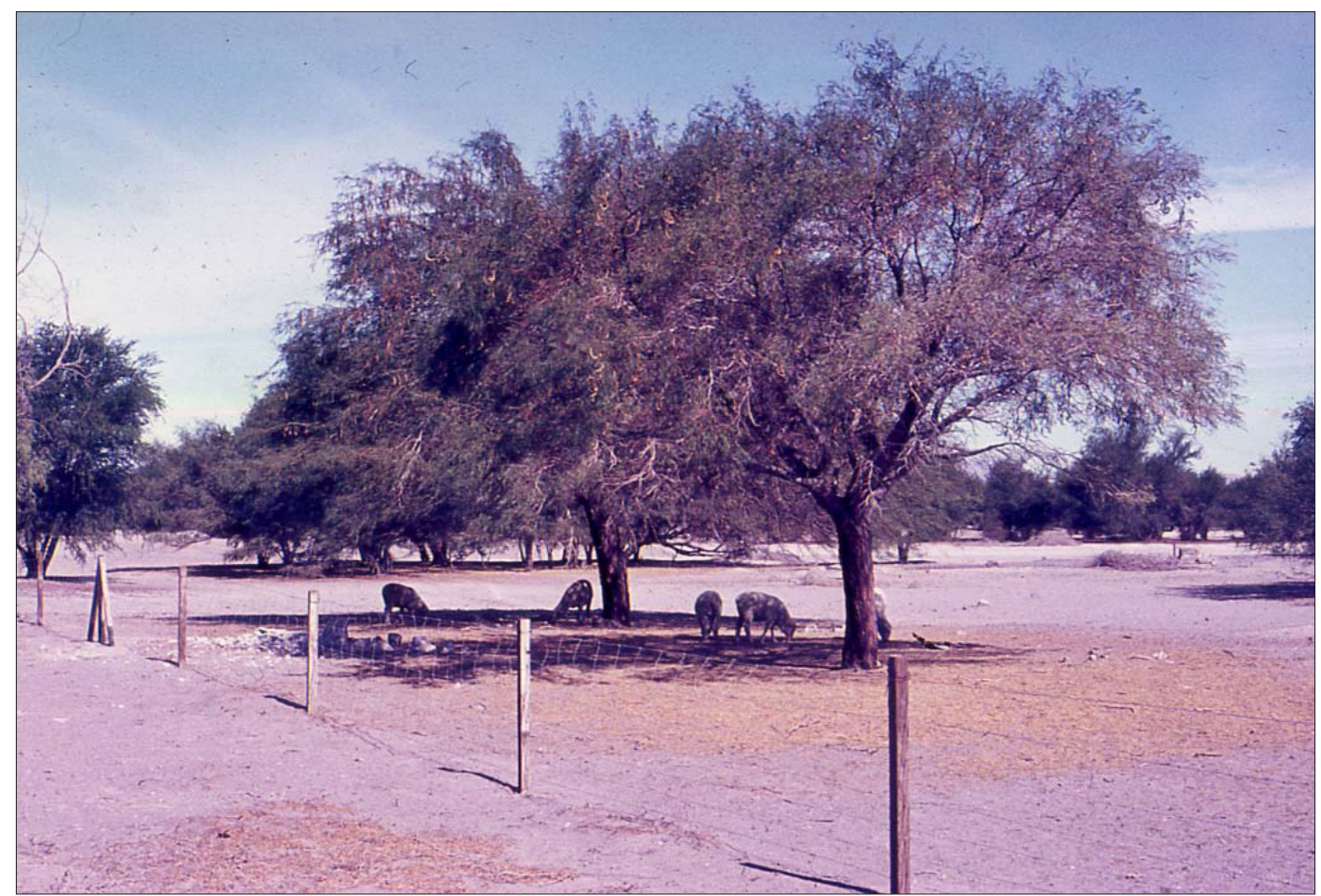

Imagen 7. Ganadería en la Pampa del Tamarugal.

Fuente: Archivo Personal. Foto tomada por K. Von Buch en diciembre 1969.

83 Castro 2004, p. 210-215; Castro 2005, p. 63-91.

84 Entre 1879 y 1883 Tarapacá estuvo bajo la condición de territorio anexado a cargo de un jefe político. En 1884, tras el traspaso definitivo a la soberanía de Chile, pasó a ser provincia dirigida por un intendente, situación que perduró hasta 1975 donde pasó a ser región, condición que mantiene hasta la actualidad.

85 Hasta donde sabemos, en base a referencias documentadas, la concesión de hectáreas baldías fue la única modalidad establecida con fines de reforestación, aunque cabe la posibilidad que también se hayan llevado a cabo plantaciones en áreas no deterioradas. 
quizás el más decidido empresario del rubro, una superficie de 10 hectáreas baldías en el sector de Canchones para que formara un bosque de algarrobales ${ }^{86}$, medida que se replicó durante estos años en otros sectores de la Pampa del Tamarugal como Huaycazo, Challapozo, Challapocito, Pintados, Gramadal de Bella Vista, Puquios de Guatacondo y Puquio de Quillagua ${ }^{87}$. Hacia 1893, como resultado de este tipo de iniciativas, las estadísticas arrojaron la cantidad de 22.153 árboles plantados sólo en la zona de Canchones, tendencia que se intensificó en 1900 al contabilizarse unos 300.000 algarrobos plantados mediante el esfuerzo de comerciantes tales como Juan Bautista Gallegos, Bernardo Digoy y Luis Montenegro, además del propio Dassori ${ }^{88}$.

A pesar de que estas plantaciones privadas no lograron recomponer el colapso ecológico provocado por la industria salitrera desde sus inicios, sí constituyeron un freno al interés exclusivamente depredador de algunos individuos, además de ayudar al énfasis fiscalizador que comenzó a tener la administración provincial referente a la tala descontrolada de los árboles nativos. Uno de los primeros registros que tenemos de este proceso siendo Tarapacá parte soberana de Chile, es del 19 de noviembre de 1883 cuando el inspector general de salitreras, E. Canninghan, le hace saber a su superior jerárquico su preocupación por la depredación del bosque y la urgente necesidad que había de prohibir el talaje indiscriminado:

Pongo en conocimiento de V.S. que desde hace mucho tiempo algunos vecinos del interior de la provincia, sin autorización alguna, se permiten la corta de árboles tanto en el pequeño bosque de la Tirana como en el cantón Lagunas, ocasionando con esto graves perjuicios no solo a los viajeros que trafican por el desierto, que dentro de poco no tendrían donde guarecerse del sol ardiente de la pampa, sino también al fisco que no saca provecho alguno de sus bosques. Sería conveniente que VS. ordenara se prohibiera por completo la corta de árboles en la pampa del Tamarugal, por convenir así a los intereses generales de la provincia ${ }^{89}$.

En respuesta, el jefe político de la provincia, Francisco Valdés Vergara, tomando en cuenta adicionalmente una denuncia por parte de la subdelegación de Pica en contra de Pedro Junoy, quien había estado por meses sacando de raíz árboles otorgados a su favor en concesión a cambio de un manejo regulado de poda de ramas y de extracción de especies muertas o fosilizadas para obtener leña y carbón, decide no sólo prohibir la corta generalizada de los árboles en toda la Pampa del Tamarugal, especialmente en La Tirana y el cantón de Lagunas, sino también rescindir su contrato y multarlo por un monto de \$500 como resultante de una tasación de \$25 por cada árbol eliminado, y una mensualidad única de $\$ 30^{90}$. Además, con fecha 21 de noviembre, emitió una circular a los subdelegados en donde los instruía a vigilar el bosque para evitar hechos como el sancionado por él directamente, como los denunciados por el inspector gene-

86 Archivo Nacional de Chile, Fondo Intendencia de Tarapacá (en adelante ANCh-IT), volumen 96, Iquique 16/11/1886, s/f.

87 Billinghurst 1893.

88 Bermúdez 1977, p. 420-421.

89 El Veintiuno de Mayo, Iquique 22/11/1883, p. 3. El subrayado es nuestro, y con ello queremos resaltar que el adjetivo utilizado por Canninghan describe con precisión el deterioro que había alcanzado el bosque por falta de fiscalización y manejo.

90 ANCh-IT, volumen 54, Iquique 23/11/1883, fol. 154r; ANCh-IT, volumen 61, Pica 19/11/1883, s/f. 
ral de salitreras ${ }^{91}$.

La labor de este jefe político se vio respaldada por una campaña periodística, iniciada en el mes de septiembre de 1883, en contra de los cortadores de leña que hacían esta labor en las cercanías del pueblo de La Tirana y Cerro Gordo ${ }^{92}$. Este ejercicio de denuncias y propuestas públicas a través de la prensa, terminó derivando en una corriente de opinión a favor de la protección forestal y en una suerte de presión social hacia las autoridades locales para que materializaran distintas diligencias con este fin. El resguardo de la foresta desértica se convirtió, de este modo, en una política regular de la administración provincial, provocando continuos rechazos a solicitudes de superficies boscosas, tales como la que expresó el intendente Gonzalo Bulnes en septiembre de 1884 ante la petición de exclusividad por veinte a treinta años para cortar el monte del valle del río Loa, ubicado en una longitud de dos leguas desde la desembocadura hacia el interior, con el propósito de hacer leña:

\begin{abstract}
Respecto a las maderas del río Loa, debo decir a US. [ministro de Hacienda] que no conozco la cantidad de leñas que existen. Pero en cualquiera que ella sea en ningún caso debe US. conceder el derecho de sacarlas. Las prescripciones del código de minería no pueden aplicarse a estos lugares desde que los puntos en que hay árboles son excesivamente reducidos de lo que proviene que tengan un valor tan considerable que se mencionan individualmente en los inventarios de cada heredad. Pretender cortar los escasísimos grupos que aun se conservan en la pampa en nombre del código de minería aconseja suprimir los únicos sitios de sombra y descanso que hacen posible los cateos en el desierto ${ }^{93}$.
\end{abstract}

Bajo estos mismos términos, a fines de 1884 el juez de Iquique procesó a un tal Pedro Cautín por no haber acatado la prohibición de la Intendencia de talar los árboles y extraer leña de las áreas fiscales de la Pampa del Tamarugal ${ }^{94}$. Podemos mencionar también, la negativa del intendente Anfión Muñoz, firmada a comienzos de 1886, a la petición de Carlos Navarrete y Vicente Ariztía para ocupar un bosque de tamarugos, talarlo y destinar el terreno a la agricultura, argumentando que era "inconveniente esta concesión de terreno en la Pampa del Tamarugal por pedirse la casi destrucción de ese bosque cuya conservación es necesaria alli"s5, así como el rechazo a la solicitud de Pedro José Pérez, a mediados de 1886, para explotar un terreno arbolado al oriente de los cultivos hortícolas de la quebrada de Tasma con el fin de hacer leña y carbón ${ }^{96}$.

La preocupación ante la persistencia de la tala ilegal, intensificado a partir de los serios inconvenientes que estaba provocando la corta de árboles para obtener leña y carbón, se tradujo en una circular de la intendencia de Tarapacá emitida a mediados de 1885 y en donde se les reiteró a los subdelegados del interior de la provincia la estricta vigilancia del bosque existente en la Pampa del Tamarugal97. A diferencia de lo ocurrido en 1883 ante el mismo tipo de instructivo, esta vez los subdelegados, parti-

91 El Veintiuno de Mayo, Iquique 22/11/1883, p. 3.

92 El Veintiuno de Mayo, Iquique 14/9/1883, p. 2.

93 ANCh-IT, volumen 65, Iquique 1/9/1884, f. 161.

94 ANCh-IT, volumen 46, Iquique 27/11/1884, s/f.

95 ANCh-IT, volumen 97, Iquique 9/4/1885, f. 93.

96 ANCh-IT, volumen 95, Iquique 1886, s/f.

97 ANCh-IT, volumen 93, Pozo Almonte 29/5/1885, s/f. 
cularmente el de Pozo Almonte, le hicieron ver a la máxima autoridad tarapaqueña que esta medida solo podía llegar a ser efectiva con la designación de un funcionario a cargo de fiscalizar las acciones indebidas y proteger el bosque ${ }^{98}$. Tomando en cuenta el peso de esta opinión, amparada en evidencias tales como la lejanía de algunas áreas del bosque, particularmente el de La Soledad, y los múltiples puntos de los cuales se sacaban impunemente los troncos, el intendente Fuentes resuelve nombrar el 20 de mayo de 1885 a Manuel Hidalgo como guardabosque ${ }^{99}$, el segundo en cumplir específicamente este rol en la provincia de Tarapacá tras el que designó en 1873 la Comisión Agricola del Tamarugal.

Más allá de los efectos positivos de todas estas medidas y el evidente progreso en materias de resguardo estatal del bosque nativo tarapaqueño, las mentes más lúcidas de la provincia reclamaron hacia la década de 1890 modificaciones cualitativas en el manejo del recurso forestal. Este fue el caso de Guillermo Billinghurst que planteó la urgencia, comparando las leyes chilenas y francesas de la época, de no solo impedir la destrucción de los árboles, sino el abocarse de modo privilegiado a su regeneración:

La legislación chilena se limita a impedir la destrucción de los árboles y arbustos. La francesa, como se ha visto, no descuida el punto concerniente a la regeneración; y al efecto establece primas y subvenciones en determinados casos, y en otros compele a los propietarios hacer por su cuenta plantaciones que la seguridad y conservación de los terrenos reclaman ${ }^{100}$.

Detrás de esta postura, estaban sus estimaciones de que el algarrobo a los cinco años ya tenía valor comercial como alimento para los animales, y a los siete alcanzaba una altura productiva de 5 metros ${ }^{101}$. Francisco Beze, corroborando esta información décadas más tarde, afirmó que esta especie tenía la gran virtud de reproducirse rápidamente, empezando a dar sus frutos a partir de los cinco años, y a los diez ya arrojaba 5 quintales españoles (500 kilos) anuales en legumbres ${ }^{102}$. Es decir, evitar la depredación e impulsar la reforestación, no solo tenía un valor medioambiental, sino igualmente económico.

Tomando en cuenta la experiencia de dos décadas en cuanto a la complejidad del manejo de los recursos forestales del desierto y las opiniones influyentes que avalaban esta vinculación, en el año 1900 el delegado fiscal de salitreras promovió un lúcido plan para lograr un equilibrio entre la conservación y recuperación del bosque de tamarugos y algarrobos y su utilización económica. Tres fueron los puntos centrales de su planteamiento: 1) desarrollar la agricultura en la Pampa del Tamarugal a gran escala como una forma de precaverse del término proyectado de la industria salitrera; 2 ) conceder en propiedad cierta extensión de terrenos a toda persona que lograse obtener agua por pozo o socavón; 3) otorgar el mismo beneficio anterior a los que plantasen y cultivasen un número determinado de algarrobos y tamarugos ${ }^{103}$. En su con-

98 ANCh-IT, volumen 93, Pozo Almonte 29/5/1885, s/f.

99 La Industria, Iquique 20/5/1885, p. 3.

100 Billinghurst 1893, p. 166-167.

101 Billinghurst 1893, p. 166.

102 Beze 1920.

103 Bermúdez 1977, p. 419. 
cepción, tales medidas debían concretarse en "una ley que diera la propiedad del suelo a los que hicieran los trabajos indicados", transformándose de este modo en "precursora de la industria agrícola en esta provincia, asegurándose así una vida estable y permanente"104.

Las sugerencias del delegado fiscal de salitreras se tradujeron, como lo observó Manuel Salinas, un ex ministro de Hacienda, en un "notable desarrollo" de las "plantaciones de algarrobo, cuya semilla tienen variadas aplicaciones industriales"105, y en un precursor proyecto de ley de su autoría presentado al Senado por el presidente Ramón Barros Luco el 29 de mayo de 1903. Este cuerpo legal, de 15 artículos, propuso no solo beneficiar a los que plantaran tamarugos o algarrobos en la Pampa del Tamarugal, sino también regular su manejo mediante criterios estrictos de cuándo y cómo se podían cortar los árboles sin dañar la superficie forestal. Del texto completo, de particular interés resultan los siguientes puntos:

Art.1. Se autoriza al presidente de la República para que adjudique en propiedad a los particulares que lo soliciten terrenos susceptibles de cultivo en la provincia de Tarapacá, con arreglo a las disposiciones que establece la ley.

Art.4. Los adjudicatorios quedarán obligados a dotar de agua los terrenos que obtengan, a labrarlos y cultivarlos y hacer en ellos plantaciones de árboles.

Art.5. Cuando la concesión se refiera a la clase de terrenos cultivables de la Pampa del Tamarugal que se designa con el nombre de canchones, los concesionarios quedarán obligados a plantar en el término de cuatro años a lo más, treinta árboles de dos años de edad por cada hectárea.

Art.6. Cuando la concesión se refiera a terrenos que no sean adaptables al cultivo por medio del sistema de canchones, los adjudicatorios dispondrán de un plazo de seis años para cumplir con la obligación que establece el artículo precedente.

Art.13. El Estado reconoce la propiedad de los terrenos cultivados de la Pampa del Tamarugal, en favor de los que acrediten haberlos ocupado y cultivado por el término de un año, a lo menos, antes del 1 de mayo de 1903.

Art.14. La Delegación Fiscal de Salitreras, formará un catastro de los terrenos cultivados y de los poseídos sin cultivar en la Pampa del Tamarugal, y llevará un registro de los terrenos que se concedan con arreglo a la presente ley.

Art.15. Queda prohibida la corta de árboles en la Pampa del Tamarugal ${ }^{106}$.

Como se puede observar, lo más interesante de este proyecto fue sancionar que los particulares recién podían cortar los árboles de su propiedad cinco años después de la fecha de promulgada esta ley previo permiso del intendente de la provincia, el que autorizaría la corta siempre y cuando lograra acreditar que en cada hectárea concedida existieran más de treinta árboles y solo por el número excedente de ellos.

A pesar que este cuerpo legal no se promulgó, vino a representar uno de los indicios más contundentes del profundo nivel que había alcanzado en la provincia de Tarapacá, hacia inicios del siglo XX, la discusión pública sobre la problemática del desarrollo regional vinculada al manejo del bosque del Tamarugal y su potencial agrícola. Un planteamiento que fue permeado por distintas posturas de grupos y personajes influyentes de Iquique que veían la necesidad perentoria de generar sectores productivos interconectados y sustentados en una adecuada inversión fis-

104 Ibidem.

105 Salinas 1903, p. 37.

106 Salinas 1903, p. 36-40; Salas Lavaqui 1908, p. 661-664. 
cal en obras públicas (caminos, vías férreas y embalses) con el propósito de afianzar una economía local diversificada en tres ejes (agricultura, comercio interregional y minería), además de estable, proyectada a largo plazo y no dependiente de la industria salitrera ${ }^{107}$. De hecho, el argumento medular que el delegado fiscal de salitreras planteó en 1903 para justificar su propuesta, que derivó en un proyecto de ley presentado al poder legislativo, fue afirmar de modo tajante que "si fuera posible dotar de agua estos terrenos [de la Pampa del Tamarugal], se lograría asegurar la vida de la provincia de Tarapacá, que hoy se sostiene casi exclusivamente de industrias inestables y transitorias, como la explotación de sus depósitos de nitratos"108; el mismo planteamiento que manifestó nueve años más tarde Manuel Urrutia, administrador de la Aduana y Tesorería Unida de Iquique, en su memoria anual correspondiente a 1912, al afirmar que la "agricultura no es acá actualmente una industria, porque no existe en si", pero que los "extensos terrenos del Departamento se adaptan a ella y que puede resolverse con obras de irrigación para aumentar su poder productivo e incrementar, más que la misma minería, la fortuna pública y privada del país"109, y las editoriales del semanario católico Las Cuestiones Sociales al plantear, en enero de 1922, que la agricultura "es una riqueza que no está expuesta como las minas, o el salitre, a falta de utilidad, crisis, tempestades o calamidades o incertidumbre de ningún género"110 y en diciembre de 1926 que la "pampa regable puede convertirse en campo feraz, que haría barata la vida en el norte"111.

Así, la preocupación por un manejo racional de la riqueza arbórea en el marco de una estrategia de desarrollo regional, se instaló con fuerza en las primeras décadas del siglo pasado, a lo que se sumó a la distancia el fortalecimiento institucional al interior del Estado mediante la creación en 1911 de la Inspección General de Aguas, Bosques, Pesca y Caza encabezada por Federico Albert como parte del Ministerio de Industria y Obras Públicas ${ }^{112}$. De hecho, una solicitud de Ernesto Maldonado, jefe de la Sección de Bosques de la mencionada Inspección, de abril de 1914 y que decía relación con la necesidad de que la Intendencia de Tarapacá llevara a cabo un catastro de terrenos fiscales e implementara un vivero para solventar eficientemente un programa de reforestación de la Pampa del Tamarugal ${ }^{113}$, llevó al ingeniero de la provincia, Juan Carabantes, a plantearle al intendente en agosto de ese mismo año que, lo solicitado por Maldonado, era muy pertinente por la urgencia que tenía para la provincia el realizar un detallado análisis del nivel de la depredación de los montes de tamarugos y algarrobos y la forma de recuperarlos con criterios de sus-

107 Castro 2005.

108 En Riso-Patrón 1903, p. 36.

109 Memoria del Administrador de la Aduana y Tesorería Unida de Iquique al Superintendente de Aduanas. Iquique 1912. En López Loayza 1913, p. 56.

110 Las Cuestiones Sociales, $\mathrm{n}^{\circ} 46$, Iquique 12/1/1922, p. 2.

111 Las Cuestiones Sociales, $\mathrm{n}^{\circ}$ 285, Iquique 9/12/1926, p. 4.

112 Camus 2003, p. 58; Casals 1999, s/p; Yáñez y Canto 2013, p. 7.

113 Es conveniente recordar que en ese momento Juan Carabantes ostentaba el cargo de ingeniero de la provincia, por tanto, era un conocedor profundo de las potencialidades económicas de Tarapacá como de los temas desarrollistas que preocupaban a la opinión pública regional. 
tentabilidad y reproducción económica. En su opinión, era pertinente y necesario deslindar definitivamente las propiedades particulares de las fiscales ubicadas en la Pampa del Tamarugal para controlar la tala indiscriminada, como el emprender una reforestación extensiva mediante la captación adecuada de las aguas cordilleranas que bajaban a la depresión intermedia:

(...) el infrascrito puede manifestar a US. que aún existen en la pampa del Tamarugal grandes extensiones de suelo fiscal que son enteramente aptas para las plantaciones de aquella naturaleza, pero que sólo en las depresiones de esta gran pampa se pueden mantener todavía bosques de tamarugos sin que haya intervenido para nada el cultivo artificial de ellos; y muy por el contrario, aún cuando hay reglamentos supremos que prohíben la corta de esos árboles, nunca han faltado, ni faltan personas que hacen una verdadera industria con la corta de ellos, ya sea para venderlos como leña o para la fabricación de carbón de madera. (...) la primera labor de la Sección de Bosques sería la de deslindar la propiedad fiscal de la particular, punto que ya he tenido más de una oportunidad de indicar sin conseguir que se le dé la importancia que tiene, y evitar que sin derecho alguno se siga haciendo la extirpación de los bosques fiscales existentes. Después de esto, y para la propagación de las plantaciones existentes, habría que estudiar la mejor manera de aprovechar las aguas que, bajando por las quebradas que vienen de la Cordillera de los Andes, van a sumirse en la pampa, perdiéndose una gran parte de ellas ${ }^{114}$.

En estas condiciones, según su parecer, se encontraban el monte de La Soledad (frente a las quebradas de Mani, Pistala y Sijuca), el bosque del salar de Pintados y la zona arbolada comprendida entre Pozo Almonte y el oasis de Pica. Siendo esta última área la más adecuada para las plantaciones, y por ello debía tener una especial importancia establecer con precisión el deslinde de la propiedad fiscal de las particulares ${ }^{115}$.

La labor de Albert y Maldonado, a pesar que el primero nunca viajó a Tarapacá para conocer directamente el bosque de la Pampa del Tamarugal, fue relevante desde la perspectiva que las preocupaciones locales por el bosque desértico comenzaron a tener una contraparte en la administración central del Estado, además de ser tributarios de la labor de sensibilización de ambos en las altas esferas políticas para que Chile tuviera una legislación que posibilitara la preservación y uso racional de los bosques:

En el norte se han agotado casi por completo i en muchas partes tal vez no han existido nunca, ya sea por el terreno salitroso o por la sequedad estraordinaria. Llama la atención que existan parajes donde hai restos de bosques estensos cuyos troncos gruesos están, en parte o enteramente, enterrados en la arena i que sirven hoi dia para la esplotación del vecindario, como por ejemplo al norte del rio Loa en Pozo Almonte i en el cantón salitrero de Pampa-Negra, en el departamento de Pisagua. No he visitado estas rejiones, pero creo que con razón se puede preguntar si no será posible levantar otros bosques sobre los que han sucumbido

114 Archivo Regional de Tarapacá, Fondo Intendencia de Tarapacá (en adelante ART-IT), volumen 2, Iquique 24/8/1914, s/f.

115 Ibidem. 
en otras épocas. Un estudio detenido de estos parajes puede traer una contestación sobre las probabilidades de un ensayo práctico en este sentido. ${ }^{116}$.

En estos términos, el situar a partir de 1914 el bosque del Tamarugal al interior de uno de los 21 servicios provinciales a cargo de la Sección de Bosques, particularmente ser una de las tres zonas de fomento de árboles forestales (la de Atacama entre Tacna y Antofagasta), dio cuenta por primera vez la posibilidad de reconocer este potencial en los tamarugos y algarrobos, como también visibilizar otras potencialidades de la Pampa del Tamarugal al interior del aparato estatal afincado más de dos mil kilómetros al sur ${ }^{117}$. Este diseño, que Albert lo venía impulsando largamente ${ }^{118}$, fue coincidente, en lo medular, con las aspiraciones y planteamientos de los tarapaqueños, especialmente en resaltar la estrecha vinculación entre la preservación e incremento del bosque y la agricultura asociada en un ecosistema como el del desierto de Atacama:

Quedan por hacer ensayos de aclimatación de Antofagasta a Tacna, que no se han hecho todavía por no tener los elementos necesarios para este objeto, pero creemos de urjente necesidad que el Supremo Gobierno se digne poner a disposición de la Sección los fondos i terrenos fiscales respectivos, ya que se trata de rejiones donde la existencia de los bosques es de imprescindible necesidad para la agricultura i aun para tener el agua suficiente para la bebida de sus habitantes ${ }^{119}$.

Evidentemente la institucionalidad impulsada por Albert, y secundada por Maldonado, no fue suficiente respecto a cambiar las amenazas constantes de depredación del bosque del Tamarugal. Después de todo la provincia de Tarapacá, más aún la Pampa del Tamarugal, seguía estando muy distante de donde se tomaban las decisiones, acentuando de paso esta lejanía, un desconocimiento en muchas de las esferas de la administración fiscal vinculadas al área forestal o afines, del real valor de los tamarugos y algarrobos. La postura del ingeniero José del Carmen Fuenzalida manifestada en 1915 es un claro ejemplo de este tipo de inconveniente. Para él irrigar el Tamarugal no conllevaba ningún beneficio, ya que sobre esta iniciativa debía privilegiarse el "espíritu nacional" a debida cuenta que "sobre las cuentas alegres del cultivo de los campos de Tarapacá i especialmente de la Pampa del Tamarugal, está el salitre, la principal fuente de producción nacional"120, es decir, el lado opuesto a las reivindicaciones de los tarapaqueños que veían en la prioridad fiscal por la renta salitrera una expresión de un centralismo exacerbado. En estos términos, Ernesto Maldonado fue oportuno y perentorio en señalar en 1918 que, a pesar de todo el potencial del tamarugo, "ha permanecido hasta la fecha casi ignorado para los que se han ocupado

116 Albert 1903, p. 49. La valoración y conocimiento del bosque del Tamarugal, Federico Albert la asentó a través de los estudios de Guillermo Billinghurst y Alejandro Cañas Pinochet. El primero ingeniero y el mayor estudioso de la geografía de Tarapacá entre fines del siglo XIX e inicios del XX; el segundo, en tanto, gobernador del departamento de Pisagua en los años 1880 y también estudioso de la agricultura tarapaqueña y su potencial económico.

117 Camus 2003, p. 60. Las otras dos zonas eran San Fernando y Linares.

118 Albert 1901, p. 92-93; Albert 1903, p.49; Albert 1909, p. 11-12.

119 Albert 1910, p. 6.

120 Fuenzalida 1915, p. 507. 
de las especies arbóreas nacionales", no obstante, que "por el área natural que ocupa, los suelos sobre los cuales crece y los productos que proporciona, merece la pena que se estudie su conservación y cultivo" 12 , dejando en evidencia que posturas como la de Fuenzalida no tenían sustento científico, siendo posiciones estrictamente políticas.

Bajo este contexto de fortalecimiento institucional al interior de la administración del Estado, en octubre de 1916 la Municipalidad de Iquique decretó, por una parte, la prohibición de la corta ilegal de árboles en la Pampa del Tamarugal y, por otra, solicitó al gobierno que le confiara la custodia de este bosque con la intención de afianzar una gestión más integral que focal en lo referente a la preservación del recurso ${ }^{122}$, rebatiendo con ello la afirmación del intendente Recaredo Amengual aparecida en su memoria anual, de que el patrullaje policial había "traído como resultado la extirpación de la corta fraudulenta de esos árboles que, siendo de propiedad fiscal, estaban siendo explotados por particulares"123.

En consonancia con la solicitud consistorial, y de algún modo revitalizando indirectamente la iniciativa frustrada de 1873, dos años más tarde Ernesto Maldonado, siendo la máxima autoridad de la Inspección General de Bosques, Pesca y Caza en reemplazo de su mentor Federico Albert, propuso como una manera efectiva de proteger el bosque desértico de Tarapacá la creación de una Reserva Forestal del Tamarugo ${ }^{124}$.

Adhiriéndose a este impulso por recuperar el bosque desértico, en 1919 el ingeniero Luis Armijo retomó la idea de irrigar la Pampa del Tamarugal trasvasando aguas cordilleranas. Para ello, estudió, siguiendo los antecedentes elaborados por sus antecesores, las quebradas de Camiña, Aroma, Tarapacá, Guatacondo y Maní, llegando a la conclusión que las de Aroma y Tarapacá se prestaban para aumentar el caudal de sus aguas y trasladarlas hacia la pampa boscosa del Tamarugal para regar una superficie de 1.828 hectáreas ( 500 con la primera y 1.328 con la segunda), siendo para ello necesario que en la quebrada de Aroma se construyera un embalse y en la de Tarapacá obras de canalización ${ }^{125}$. La idea de Armijo con esta infraestructura hidráulica, fue complementar e incrementar la disponibilidad de agua en toda la zona del Tamarugal, la que se obtenía mediante la extracción por pozos y el sistema de capilaridad de los canchones, de modo de tener con regularidad una cantidad suficiente que hiciera posible y sostenible en el tiempo desarrollar una actividad agrícola a gran escala y, además, reforestar intensamente parte o la totalidad de las hectáreas boscosas depredadas durante el ciclo salitrero.

La necesidad perentoria de concretar este $\mathrm{u}$ otro proyecto en orden a recuperar

121 Maldonado 1918, p. 65.

122 ART-IT, volumen 4, Copiador de Oficios 1916-1917, Iquique 24/10/1916, s/f.

123 Memoria Anual Intendencia de Tarapacá 1919, p. 11.

124 Maldonado 1918, p. 66. Desconocemos si Maldonado tuvo alguna referencia de la Comisión Agrícola Pampa del Tamarugal impulsada durante el gobierno del presidente Pardo, cuando Tarapacá estaba bajo soberanía del Perú. La revisión de sus escritos referidos a los bosques de tamarugos y algarrobos del norte de Chile no nos ilustran sobre el particular, aunque podemos suponer que, al igual que Albert, leyó el trabajo de Guillermo Billinghurst sobre la irrigación de Tarapacá donde se hace mención a esta iniciativa que fue encabezada por Miguel Valle-Riestra.

125 Armijo 1919, p. 314. 
el bosque y, además, repotenciar la agricultura de los canchones que se practicaba en su interior, la dejó en evidencia el propio Ernesto Maldonado en 1925 al mencionar que en la región norte "la extensión ocupada por bosques apenas alcanza al 1/2 por mil de la superficie del suelo, que asciende a 186,710 kilómetros cuadrados"126. Un escenario contraproducente para quienes, como Heinrich Fröehlic y Peter Müffeler, habían procedido entre 1927 y 1928 a comprar cuatro hectáreas de canchones en el lugar llamado Los Puquios, aledañas a los pueblos de la Huayca y La Tirana, para producir alfalfa, semillas de bajo costo destinados a la crianza de gallinas y plantar uvas con fines vinícolas, creando el primer viñedo de la Pampa del Tamarugal ${ }^{127}$.

Tras el ocaso definitivo de la industria salitrera hacia fines de los años 1920 y la década de 1930, y la no concreción de ninguna de las propuestas levantadas por autoridades, funcionarios fiscales y particulares tendientes a crear una instancia de protección y manejo del bosque, la venta de leña y carbón pasó a constituir una actividad preponderante ${ }^{128}$, más aún cuando, por un lado, no había control efectivo alguno de la tala ilegal de tamarugos y algarrobos, incluyendo los montes de propiedad del fisco, y, por otro, existía complicidad de funcionarios corruptos y de comerciantes acaudalados de Iquique. Una denuncia de carabineros cursada en agosto de 1928 en contra del subdelegado de Lagunas por permitir la corta ilegal del monte La Soledad a cambio de una contribución entre $\$ 0,50$ y $\$ 1$ por cada saco de carbón que se obtuviera ${ }^{129}$, es una clara muestra de la amenaza que se cernía sobre la Pampa del Tamarugal. En 1929, en tanto, la denuncia e investigación policial referida a la corta ilegal de tamarugos para hacer leña y carbón en la parte llamada Pozo Grande, donde estaban los montes de Sara y Trinidad, dejó en evidencia los alcances delictivos que había adquirido esta práctica, al dejarse constancia que el que cortaba los árboles y producía la leña y el carbón era Juan Morales Mamani en calidad de arrendatario del comerciante Arturo del Río, uno de los caciques políticos de la provincia de Tarapacá, que se había apropiado indebidamente de este predio, de propiedad fiscal, mediante falsificación de documentos. Por si fuera poco, al amparo de esta investigación se supo que en el pueblo de Chayaposo, situado al sur de La Tirana, residía un individuo llamado Luis Funoy que se había apoderado de tres leguas cuadradas de terrenos fiscales haciendo un uso indiscriminado de los árboles ${ }^{130}$. Ante la gravedad de estos hechos, el subdelegado de Pozo Almonte le planteó con urgencia al intendente que:

Efectivamente hace tiempo personas inescrupulosas y sin derecho alguno se ocupan clandestinamente de la corta de árboles de Tamarugos de propiedad fiscal aprovechando sin duda alguna la falta de vigilancia de los Carabineros por tener otras atenciones que atender, agregado a esto que la pampa es demasiado grande con una infinidad de caminos en distintas direcciones, es por esto que la vigilancia de los Carabineros por muy eficaz que ella sea no podrán obtenerse los resultados que se persiguen. Estima Sr. Intendente el infrascrito que mientras se designe una comisión de guarda bosques con residencia en La Tirana o Cancho-

126 Maldonado 1925, p. 70.

127 Melcher 2004, p. 78-79.

128 Carevic 1989, p. 10.

129 ART-IT, volumen 34, Carabineros 1928, Iquique 21/8/1928, s/f.

130 ITAR, vol.1464, Comunicaciones recibidas 1929, Huara 6/8/1929, s/f. 
nes, no podrá evitarse este mal y creo que con un gasto de un mil quinientos (\$1.500) pesos mensuales para un jefe de guarda bosques con un ayudante sería suficiente y ahorraría así el fisco muchos miles de pesos y evitaría el aniquilamiento del monte y protegería el cultivo de muchas plantas en formación ${ }^{131}$.

En 1931, y no habiendo prosperado la petición del subdelegado de Pozo Almonte de nombrar a una comisión de guardabosques, un nuevo caso de ocupación y tala ilegal en terrenos fiscales se verificó en el lugar llamado "Chacauyo", al final de la Hacienda Huaraviña. En éste, residía un tal Gumercindo Morales que, desde hacía tiempo, disfrutaba de los bosques aledaños produciendo y vendiendo leña y carbón no teniendo título de dominio alguno que avalara su condición de propietario ${ }^{132}$. Al año siguiente, dando cuenta de la frecuencia arrolladora de la depredación del bosque, se da cuenta de la tala ilegal de los árboles aledaños a La Tirana, puntualmente en el área de los Cementerios y el Calvario ${ }^{133}$. Este caso, llevó nuevamente al subdelegado de Pozo Almonte, Alejandro Charlín, a escribirle al intendente con premura, indicándole que podía confirmar que "casi la totalidad de sus habitantes se dedican a esta industria y estimo no tan fácil evitarlo, más si se toma en cuenta la situación del momento", es decir la depresión económica y alta cesantía provocada por la crisis terminal de la industria salitrera, por ello y en "resguardo de los intereses nacionales, cual es evitar en lo sucesivo se repita la corta de árboles fiscales, difícil por la distancia a las autoridades de velar por su cuidado" se atrevía a sugerirle que, al no haber un guardabosque, se podría "controlar la procedencia" de los tamarugos obligando a todo camión a traficar en horas hábiles y a su paso por Pozo Almonte o demás Retenes de Carabineros, obtener una guía de Libre Tránsito, que indique el nombre del remitente y del destinatario"134.

La reacción del intendente Julio Febres Fuenzalida fue enviarle un oficio al ministro de Tierras y Colonización dando cuenta del robo de los árboles fiscales en los alrededores del pueblo de La Tirana, señalándole que eran actos difíciles de evitar debido a lo apartado de tales lugares y a la escasez de personal, y que por ello le pedía tener presente su oficio del 28 de enero de 1932 donde proponía a Frank M. Nicholls como inspector de bosques de Tarapacá ${ }^{135}$. La respuesta del ministro no se dejó esperar y de modo tajante le señaló que, por disposición de la ley N5005, "no se podrá nombrar por todo el año a empleados nuevos, y que tampoco se podría contratar a jornal porque no hay fondos" 136 , pero que bajo estas circunstancias pensaba que sería beneficioso poner en práctica la medida propuesta por el subdelegado de Pozo Almonte, en orden a fiscalizar todo camión que traficara en horas hábiles mediante una guía de libre tránsito a efecto de verificar quién vendía y quién compraba y el origen de la leña y el carbón. Junto a lo anterior, le sugirió que para sancionar a los

131 ITAR, vol.1464, Comunicaciones recibidas 1929, Pozo Almonte 20/7/1928, s/f.

132 ITAR, vol.1560, 1931, Oficios enviados 1931, Iquique 10/4/1931, s/f.

133 ITAR, vol.1575, Comunicaciones recibidas 1932-1933, Canchones 28/1/1932, s/f.

134 ITAR, vol.1575, Comunicaciones recibidas 1932-1933, Pozo Almonte 2/2/1932, s/f.

135 ITAR, vol.1575, Comunicaciones recibidas 1932-1933, Iquique 8/2/1932, s/f.

136 ITAR, vol.1575, Comunicaciones recibidas 1932-1933, Santiago 13/2/1932, s/f. 
infractores se remitiera a las disposiciones establecidas para estos casos en la Ley de Bosques que se había promulgado el año anterior ${ }^{137}$, cuestión que no sabemos si efectivamente se aplicó. Lo que si consta, es que la prefectura de carabineros de Iquique le ordenó a la comisaría de Pisagua que designara personal del retén de Pozo Almonte para efectuar patrullajes dos veces por semana a los bosques de La Tirana con el objetivo de fiscalizar la procedencia de la leña ${ }^{138}$.

En este escenario nada de propicio, la plantación de tamarugos y algarrobos por parte de Luis Junoy entre fines de la década del 30 e inicios del decenio del 40 del siglo pasado, fue la única reforestación privada de cierta envergadura conocida con posterioridad al término del ciclo salitrero ${ }^{139}$, denotando un cambio en los criterios de cómo explotar el monte tomando en cuenta el actuar de su padre, Pedro Junoy, que había sido fuertemente sancionado en 1883 por la intendencia de Tarapacá por cortar ilegalmente árboles en la zona de Canchones, bosque entregado a su manejo como parte de una concesión gubernativa destinada a la preservación y recomposición arbórea del lugar. En los mismos términos, la resolución del gobierno de designar en 1941 una comisión de alto nivel para estudiar el regadío de la Pampa del Tamarugal y afianzar los resultados de las distintas perforaciones exploratorias que habían estado llevando a cabo desde hacía algunos años tanto la Dirección de Obras Públicas como la Caja de Colonización con el propósito de encontrar aguas artesianas para regar áreas adyacentes a los pozos que estaban en funcionamiento ${ }^{140}$, cerró un ciclo donde se buscó tener la disponibilidad suficiente de agua para un uso agrícola intensivo en el Tamarugal y los valles inmediatos, e incrementar el cultivo de pastos naturales y arbustos de ramoneo destinados a la ganadería.

Si bien en este lapso, que abarcó los primeros sesenta años de administración chilena de la provincia de Tarapacá, nunca se materializó el riego masivo, si lo hizo la actividad ganadera décadas más tarde, poniéndose de este modo fin a un periodo dinámico en propuestas y planteamientos en torno a la Pampa del Tamarugal y la conservación y uso económico racional de su bosque, pero a la vez dramático desde el punto de vista de la depredación de este monte impulsado por la profunda crisis económica que dejó en esta zona el término de la industria salitrera y la poca capacidad de las autoridades por ejercer un control efectivo de la tala ilegal. De este modo, lo que caracterizó el periodo chileno fue el de expectativas nunca concretadas a pesar de que desde 1911 el Estado incrementó la institucionalidad y la legislación referida a la conservación y uso de la riqueza arbórea.

137 ITAR, vol.1575, Comunicaciones recibidas 1932-1933, Santiago 24/2/1932, s/f.

138 ITAR, vol.1575, Comunicaciones recibidas 1932-1933, Iquique 29/3/1932, s/f. La tala ilegal sigue siendo un problema hasta la actualidad, constituyendo su fiscalización una tarea prioritaria de la entidad estatal chilena que está a cargo del bosque de la Pampa del Tamarugal, tal como lo denuncia una reciente noticia aparecida en el principal periódico de la zona titulada "La CONAF detectó corta no autorizada de tamarugos". La Estrella de Iquique, Iquique 24/4/2018, p. 11.

139 Carevic 1989, p. 11.

140 Jaramillo 1941, p. 168-172. 


\section{Comentarios finales}

En 1963, a través de la sección agrícola del Departamento Tarapacá del Instituto CORFO Norte (INCONOR), se dio inicio a un ambicioso programa forestal-ganadero cuyo objetivo principal fue el de poblar de tamarugos y algarrobos determinadas áreas de la Pampa del Tamarugal para obtener sus frutos y alimentar con ellos una masa ganadera ovina con fines netamente comerciales. Entre 1963 y 1972, al amparo de esta experiencia, se plantaron 13.840 hectáreas de tamarugos y algarrobos en los salares de Refresco, Bellavista y Zapiga a cargo de INCONOR como parte del Programa Forestal Ganadero de la Pampa del Tamarugal, lo que llegó a ser la mayor plantación de especies nativas realizadas durante el siglo $\mathrm{XX}^{141}$. Tras el ascenso de los militares al poder en 1973, este programa de reforestación masiva se mantuvo mínimamente hasta que entre 1983-1986 se reactivó con nuevas plantaciones ejecutadas por la Corporación Nacional Forestal (CONAF) y en 1987 con la creación de la Reserva Nacional Pampa del Tamarugal, iniciativa que sin embargo tuvo su primer plan de manejo diez años después ${ }^{142}$.

Mirada la problemática medioambiental del bosque de la Pampa del Tamarugal en perspectiva histórica, lo primero que queda en evidencia es que cuando se operó con criterios estrictamente económicos, sobre todo asociados a la minería, los recursos forestales sufrieron un deterioro significativo, en cambio, cuando se buscaron modos equilibrados entre las necesidades económicas y la preservación de la biomasa, la mantención (aunque parcial) del frágil ecosistema boscoso del desierto tarapaqueño fue más fructífera ${ }^{143}$. Lo segundo que emerge es que, independiente de los muy acotados logros, las iniciativas tanto fiscales como empresariales orientadas a proteger los tamarugos y los algarrobos sí representaron acciones antecesoras respecto a una idea de manejo integral del bosque en correspondencia a una estrategia de desarrollo, es decir, asentar la idea de que era posible la preservación del recurso y la necesidad de generar impulsos productivos a gran escala. En efecto, el que las diversas propuestas hayan tenido al fortalecimiento de una "industria agrícola" como uno de sus soportes, permitió que el tema de la utilidad económica y la preservación del bosque de la Pampa del Tamarugal se insertara en una apuesta entendida como de largo plazo ${ }^{144}$.

Pero también el carácter precursor de parte importante de estas iniciativas tuvo que ver con el poner en la opinión pública -a partir de los mecanismos de conservación, las ideas económicas y las formas de gestión propuestas- un concepto de área administrada. En efecto, el decreto del gobierno del presidente Manuel Pardo que puso en 1873 el bosque de la Pampa del Tamarugal bajo la tutela de una Comisión Agrícola como resultado del proyecto del ingeniero Buchwald de 1872, es una de las más tem-

141 Carevic 1989, p. 11.

142 Plan de Manejo Reserva Nacional Pampa del Tamarugal 1997, p. 24 y 37-38.

143 La relación expansión productiva, crecimiento demográfico urbano y deterioro de medioambientes boscosos fue una constante durante el siglo XIX en Latinoamérica. En Cuba la deforestación tuvo que ver con la industria del azúcar (Funes 2005), en Brasil con el requerimiento de leña para uso doméstico de las ciudades (Lobato 2011), en Argentina y México por el ferrocarril y la minería (Rojas et al. 2014; Simón Ruiz 2011), y en Chile por la minería cuprífera (Folchi 2001). 144 Los alcances más generales de esta discusión se pueden revisar en Castro 2004 y 2005. 


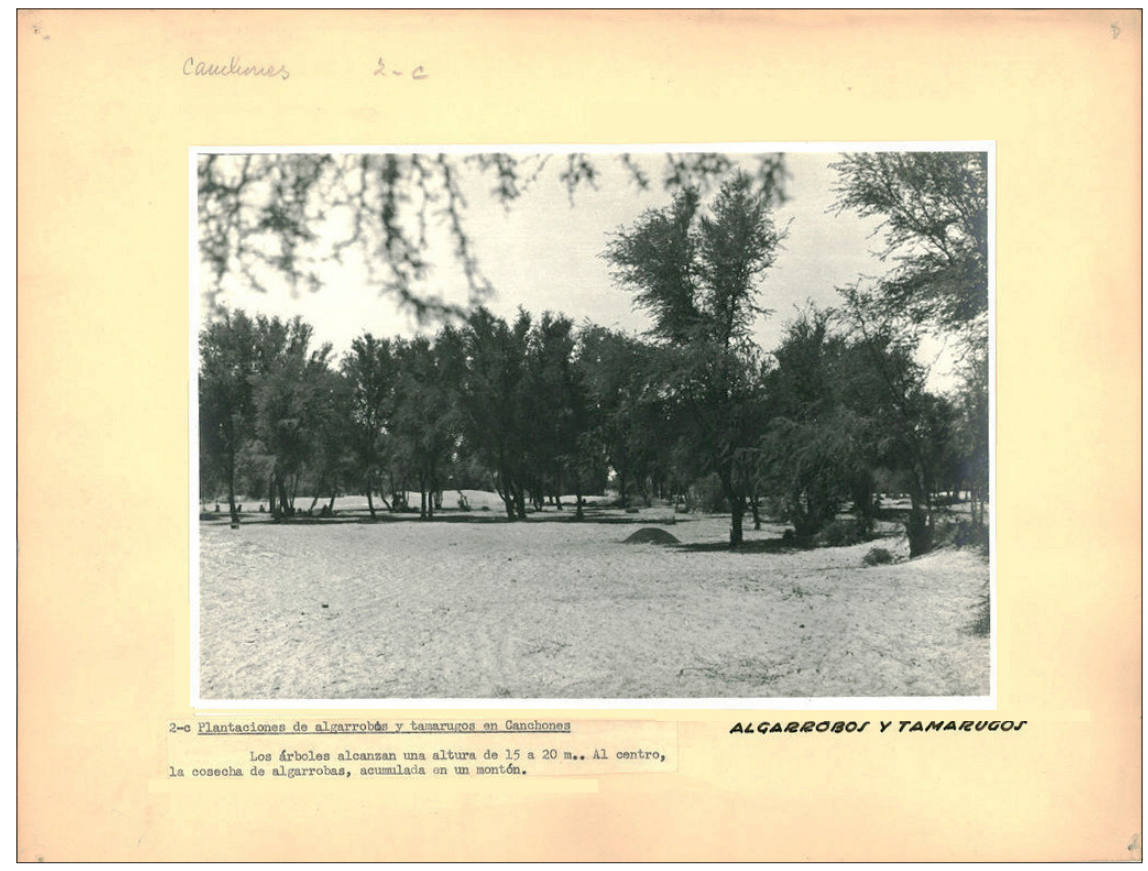

Imagen 8. Reforestación de Algarrobos y Tamarugos en el área de Canchones.

Fuente: Coleccion Documental Enciclopedia Chilena, ECH3343. En: www.ben.cl.

pranas experiencias en los registros de la historia ambiental latinoamericana referida a recuperar y conservar el recurso forestal bajo un enfoque integral acotado a un área protegida definida a partir de criterios medioambientales, cuestión notable si se toma en cuenta que en Estados Unidos se crea el primer parque nacional de la historia mundial, Yellowstone, en $1872^{145}$, y que en España en 1876, al amparo de la idea de que la repoblación forestal formaba parte de la regeneración de la patria, se le encomienda a la guardia civil la custodia de los bosques públicos ${ }^{146}$.

El atributo predecesor de la Comisión Agrícola de Tamarugal, resalta todavía más al consignar la contratación de un guardabosque, el primero de la historia forestal peruana al entrar en funcionamiento ochenta y ocho años antes de la creación del primer parque nacional de este país, el de Cutervo, en 1961 ${ }^{147}$; un antecedente que, además, pone en entredicho la afirmación de Marc Dourojeanni que durante el siglo XIX, a pe-

145 Acrecienta la importancia de esta experiencia, el hecho de que el surgimiento de los parques nacionales latinoamericanos corresponde a la primera mitad del siglo XX (Nahuel Huapi en Argentina 1903; Vicente Pérez Rosales en Chile 1926; Rancho Grande en Venezuela 1937; Itatiaia en Brasil 1937; Islas Galápagos en Ecuador 1956). Inmaculada Simón Ruiz (2010, p. 379-380 y 2011, p. 197-209) documenta para México un caso muy parecido al de la Pampa del Tamarugal referido a la declaración del bosque de Santa Fe como reserva forestal en 1876, medida que no tuvo efecto y que obligó al gobierno federal en 1898 a designar este ecosistema boscoso, para evitar la deforestación total, como área protegida bajo la denominación de Monte Vedado de Mineral del Chico, lo que en 1917 se transformó en el primer parque nacional mexicano llamado Desierto de los Leones. En este contexto de iniciativas pioneras de conservación forestal y su vinculación con procesos extractivos, el trabajo de Stephen Legg (2016) referido al bosque australiano de Victoria resulta muy interesante al demostrar que la industria del oro fue tanto el principal agente degradador de los árboles como, a la vez, la que lideró la lucha pública por su conservación al requerir este recurso.

146 Sabio Alcutén 2002, p. 136.

147 SERNAP 2012, p. 23. 
sar del alto consumo doméstico y productivo, no hubo preocupación gubernamental en el Perú por la depredación de los bosques y la necesidad de mitigación a través de la reforestación, a diferencia de lo que ocurrió en Estado Unidos, Canadá y Europa ${ }^{148}$. Pues bien, la creación de la Comisión Agrícola en 1873 demuestra lo contrario, más aún cuando esta experiencia fue el correlato de una serie de propuestas enunciadas desde los años 1840.

quivalente es esta situación para el caso chileno, donde la historia ambiental señala que el primer guardabosque fue Manuel Alvarado contratado en 1914 para resguardar la Reserva Forestal Malleco ${ }^{149}$, desconociendo la designación de Manuel Hidalgo el 20 de mayo de 1885, es decir treinta años antes, como guardabosque de la Pampa del Tamarugal al amparo de criterios políticos y administrativos, instalados desde el periodo peruano, que decían relación con la existencia de un área protegida.

Así como en el periodo peruano la iniciativa de Miguel Valle-Riestra, secundada por el presidente Pardo, fue relevante, durante el periodo chileno resalta, más allá si impactaron o no en la problemática del bosque de la Pampa del Tamarugal, la labor de Federico Albert y Ernesto Maldonado. El primero, a debida consideración de la institucionalidad que partió con la creación en 1911 de la Inspección General de Aguas, Bosques, Caza y Pesca al interior del Ministerio de Industria y Obras Públicas y que culminó con la Ley de Bosques promulgada en 1931, posibilitando por primera a todos los tarapaqueños partidarios de conservar el bosque del Tamarugal contar con herramientas administrativas y legales, no obstante encontrar en las autoridades, sobre todo de nivel central, un frecuente desinterés y desconocimiento ${ }^{150}$. El segundo, en tanto, consignando su propuesta de 1918 de proteger el bosque tarapaqueño mediante la creación de una Reserva Forestal del Tamarugo, lo que lo sitúa, en lo que toca a la historia regional del norte de Chile, como una continuidad de la iniciativa de 1873 que dio una corta vida a la Comisión Agrícola del Tamarugal bajo paradigmas conservacionistas equivalentes, pero también como una idea fundacional que varios años más tarde, en 1987, daría origen a la Reserva Nacional Pampa del Tamarugal. En los mismos términos, la labor del inspector fiscal de salitreras que, con una mirada estratégica y adelantada a su tiempo, propuso en 1903 una serie de medidas que terminaron en un proyecto de ley que lamentablemente no fue aprobado en el Congreso.

148 Dourojeanni 2009, p. 42. Para reafirmar esta postura este autor señala, desconociendo el decreto del presidente Pardo de 1873, que las normativas pioneras fueron las de 1908 y 1909 del gobierno de Leguía destinada a evitar la destrucción de los árboles existentes en lugares público y el establecimiento de viveros.

149 En: http://www.conaf.cl/parques-nacionales/cuerpo-de-guardaparques/

150 Una prueba palpable de este desinterés y desconocimiento de las autoridades centrales, es el caso del ministro de Tierras y Colonización en su respuesta a la petición del intendente de Tarapacá para que ratificara su propuesta de nombrar a Frank M. Nicholls como inspector de bosques de la provincia. En su oficio, consignó equivocadamente la ubicación de la Pampa del Tamarugal en Antofagasta, bastante más al ser de Tarapacá, dejando en evidencia que el extremo norte estaba fuera de las esferas de sus intereses e, incluso, conocimiento; un rasgo bastante extendido entre las autoridades políticas de la época asentadas en el aparato central del Estado en Santiago, donde el desierto fue restringidamente sinónimo de salitre por la importancia vital que representó esta industria minera para el financiamiento fiscal mediante la renta salitrera. 


\section{Bibliografía}

ALBERT, Federico. Los bosques en el país. Santiago de Chile: Imprenta Moderna, 1903, 283p.

ALBERT, Federico. Los 7 árboles forestales más recomendables para el país. Santiago de Chile: Imprenta Cervantes, 1909, 52p.

ALBERT, Federico. La organización que se debe dar en lo futuro a los Servicios de Aguas y Bosques de acuerdo con los estudios hechos en Europa. Santiago: Imprenta Cervantes, 1910, 58p.

ARMIJO, Luis. Regadío de la Pampa del Tamarugal. Anales del Instituto de Ingenieros de Chile, 1919, n. 7, p. 291-315.

BASADRE, Jorge. Historia de la República del Perú (1822-1933). Tomo 7. Lima: El Comercio, Producciones Cantabria, 2014, 301 p.

BASADRE, Modesto. Riquezas Peruanas. Lima: Imprenta de La Tribuna, 1884, 224 p. BERENGUER, José; DAUELSBERG, Percy. El Norte Grande en la órbita Tiwanaku (400 a 1.200 d.C.). En HIDALGO, Jorge et al. (eds.), Culturas de Chile. Prehistoria: Desde sus origenes hasta los albores de la Conquista. Santiago de Chile: Editorial Andrés Bello, 1989, p. 129-180.

BERMÚDEZ, Oscar. La "agricultura sin riego" en la zona de Canchones (Tarapacá, Norte de Chile). Actas del VII Congreso de Arqueología de Chile, 1977, Tomo II, p. 409-428.

BERMÚDEZ, Oscar. El oasis de Pica y sus nexos regionales. Arica: Ediciones Universidad de Tarapacá, 1987, 153 p.

BERTRAND, Alejandro. Departamento de Tarapacá. Aspecto jeneral del terreno, su clima i sus producciones. Santiago de Chile: Imprenta de La República de J. Núñez, 1879, 35 p.

BEZE, Francisco. Tarapacá en sus aspectos físicos, social y económico. Santiago de Chile: Sociedad e Imprenta y Litografía Universo, 1920, 329 p.

BILLINGHURST, Guillermo. Estudio sobre la geografía de Tarapacá. Santiago de Chile: Imprenta de El Progreso, 1886, 120 p.

BILLINGHURST, Guillermo. El abastecimiento del agua potable del puerto de Iquique. Iquique: Imprenta Española, 1887, 187 p.

BILLINGHURST, Guillermo. La irrigación de Tarapacá. Santiago de Chile: Imprenta Ercilla, 1893, 193 p.

BLAKE, John H. Geological and Miscellaneous Notice of Tarapaca. The American Journal of Science \& Arts, 1843, n. 4, p. 1-12.

BOLLAERT, William. Observations on the Geography of Southern Peru. Including Survey of the Province of Tarapacá, and Route to Chile by the Coast of the Desert of Atacama. The Journal of the Royal Geographical Society of London, 1851, n. 21, p. 99-130. 
BONILLA, Heraclio. Un Siglo a la Deriva. Ensayos sobre el Perú, Bolivia y la Guerra. Lima: Instituto de Estudios Peruanos, 1980, 236 p.

BRÜGGEN, Juan. El agua subterránea en la Pampa del Tamarugal y morfología general de Tarapacá. Santiago de Chile: Imprenta Universitaria, 1936, 59 p.

BURKART, Arturo. A monograph of the Genus Prosopis (Leguminosae Subfam. Mimosoideae). Journal of the Arnold Arboretum, 1976, vol. 57, n. 3, p. 219-249.

CAMUS, Pablo. Federico Albert: Artífice de la gestión de los Bosques de Chile. Revista de Geografía Norte Grande, 2003, n. 30, p. 55-63.

CAREVIC, Álvaro. La Pampa del Tamarugal una visión arqueológica y etnohistórica de su utilización. Iquique: Centro de Estudios del Desierto Universidad Arturo Prat, 1989, 18 p.

CAREVIC, Felipe; CAREVIC, Álvaro; DELATORRE, José. Historia natural del género Prosopis en la Región de Tarapacá. IDESIA, 2012, vol. 30, n. 3, p. 113-117.

CASALS, Vicente. La política forestal en Chile. Una perspectiva histórica. Scripta Nova, 1999, n. 45 (16), s/p.

CASTRO, Luis. Recursos hídricos altoandinos, estrategias de desarrollo económico y proyectos de riego, Tarapacá 1880-1930. Chungara, 2004, vol. 36, n. 1, p. 205-220.

CASTRO, Luis. Regionalismo y desarrollo Regional: Debate público, proyectos económicos y actores locales (Tarapacá 1880-1930). Viña del Mar: Universidad de Valparaíso y Universidad Santo Tomás, 2005, 165 p.

CASTRO, Luis. Demanda de ciudadanía, construcción de nación y rentismo minero: los planteamientos regionalistas de los habitantes de la provincia peruana de Tarapacá (1827-1874). Temas Americanistas, 2017, n. 39, p.37-66.

COUYOUMDJIAN, Ricardo; LARRAÍN, Horacio. El plano de la quebrada de Tarapacá, de don Antonio O’Brien. Su valor geográfico y socio-antropológico. Norte Grande, 1975, vol. I, n. 3-4, p.320-361.

DOUROJEANNI, Marc. Crónica Forestal del Perú. Lima: Universidad Nacional Agraria La Molina y Editorial San Marcos, 2009, 727 p.

FLORES, Carlos. El civilismo y la cuestión del salitre, 1872-1876. Historias. Revista de Historia y Sociedad, 2000, año 1, n. 1, p. 39-47.

FLORES, Carlos. La expropiación del salitre en el Perú, 1868-1876. Patrimonialismo y estanco. Tesis para optar el Grado de Magíster en Historia. Lima: Pontificia Universidad Católica del Perú, 2018, 165 p.

FOLCHI, Mauricio. La insustentabilidad de la industria del cobre en Chile: los hornos y los bosques durante el siglo XIX. Mapocho, 2001, n. 49, p. 149-175.

FUENZALIDA, José del Carmen. La provincia de Tarapacá. Alumbramiento de aguas subterráneas, aspectos jeolójicos i principales asientos mineros. Anales del Instituto de Ingenieros de Chile, 1915, nº 11, año VI, p. 507-522.

FUNES, Reinaldo. Azúcar, deforestación y paisajes agroindustriales en Cuba, 18151926. Varia História, 2005, n. 33, p. 105-128.

GONZÁLEZ, Sergio. Guillermo Billinghurst Angulo: una biografía regional. Revista de Ciencias Sociales, 2000, n. 10, p. 4-22. 
GONZÁLEZ, Sergio. La resistencia de los tarapaqueños al monopolio salitrero peruano durante el gobierno de Manuel Pardo, desde el estanco a la expropiación (1872-1876). Chungara, 2012, vol. 44, n. 1, p. 101-114.

HIDALGO, Jorge. Proyectos coloniales inéditos de riego en el desierto: Azapa (Cabildo de Arica, 1619); Pampa Iluga (O'Brien, 1765) y Tarapacá (Mendizábal, 1807). Chungara, 1985, n. 14, p. 183-222.

INFORME DE LA COMISIÓN DE AGRICULTURA SOBRE EL PROYECTO DE IRRIGACIÓN DE LA PROVINCIA DE TARAPACÁ PRESENTADO A LA CONVENCIÓN NACIONAL. Lima: Imprenta de José Félix Moreno, 1857.

JARAMILLO, Rodolfo. Regadío en Arica y en la Pampa del Tamarugal. Anales del Instituto de Ingenieros de Chile, 1941, n. 4-5, p. 168-173.

LEGG, Stephen. Political agitation for forest conservation: Victoria, 1860-1960. International Review of Environmental History, 2016, vol. 7, p. 7-33.

LOBATO, Marcos. A política florestal, os negócios de lenha e o desmatamento: Minas Gerais, 1890-1950. HALAC, 201 1, vol. I, n. 1, p. 29-54.

MALDONADO, Ernesto. Contribución al estudio del Tamarugo. Revista Chilena de Historia Natural, 1918, año 22, n. 5, p. 65-71.

MALDONADO, Ernesto. Contribución al estudio de la industria maderera y bosque chilenos. Revista Chilena de Historia Natural, 1925, n. 29, p. 70-131.

MARTÍNEZ, José Luis. Pueblos del chañar y el algarrobo. Los atacamas en el siglo XVII. Santiago de Chile: Centro de Investigaciones Diego Barros Arana DIBAM, Facultad de Filosofía y Humanidades Universidad de Chile, 1998, 220 p.

MATHEW, William. La Firma Inglesa Gibbs y el Monopolio del Guano en el Perú. Lima: Instituto de Estudios Peruanos, 2009, 346 p.

Mc EVOY, Carmen. Homo Politicus. Manuel pardo, la politica peruana y sus dilemas 1871-1878. Lima: ONPE, Instituto Riva-Agüero PUCP, Instituto de Estudios Peruanos, 2007, $378 \mathrm{p}$.

MELCHER, Gerardo. El norte de Chile: su gente, desiertos y volcanes. Santiago de Chile: Editorial Universitaria, 2004, 148p.

MEMORIA ANUAL INTENDENCIA DE TARAPACÁ. En Memoria del Ministerio del Interior de 1916. Santiago de Chile: Ministerio del Interior, 1919.

MUÑOZ, Iván. El período formativo en el Norte Grande (1.000 a.C. a 500 d.C.). En HIDALGO, Jorge et al. (eds.), Culturas de Chile. Prehistoria: Desde sus orígenes hasta los albores de la Conquista. Santiago de Chile: Editorial Andrés Bello, 1989, p. 107129.

MÜCKE, Ulrich. Politica y burguesía en el Perú. El partido Civil antes de la Guerra con Chile. Lima, Instituto Francés de Estudios Andinos e Instituto de Estudios Peruanos, 2010, $362 \mathrm{p}$.

NÚÑEZ, Lautaro. Hacia la producción de alimentos y la vida sedentaria (5.000 a.C. a 500 d.C.). En HIDALGO, Jorge et al. (eds.), Culturas de Chile. Prehistoria: Desde sus origenes hasta los albores de la Conquista. Santiago de Chile: Editorial Andrés Bello, 1989, p. 81-105. 
NÚÑEZ, Lautaro; MORAGAS, Cora. Ocupación arcaica temprana en Tiliviche, Norte de Chile I Región. Boletín del Museo Arqueológico de La Serena, 1978, n. 16, p. 52-76.

PUELMA, Francisco. Apuntes geológicos y geográficos sobre la provincia de Tarapacá en el Perú, acompañado de una ligera noticia sobre la explotación del nitrato de soda. Anales de la Universidad de Chile, 1855, tomo XII, p. 665-673.

PLAN DE MANEJO RESERVA NACIONAL PAMPA DEL TAMARUGAL. Santiago de Chile: CONAF Región de Tarapacá y Ministerio de Agricultura, 1997.

RAIMONDI, Antonio. Provincia de Tarapacá, Lima, Libreta No2, Colección Antonio Raimondi Archivo General de la Nación del Perú. En CASTRO, Luis; GUERRERO, Pablo; FIGUEROA, Carolina, La expedición de Antonio Raimondi a la provincia de Tarapacá y la construcción estatal de un territorio nacional peruano: comentarios y transcripción de su cuaderno de campo (1853-1854). Estudios Atacameños, 2017 [1853], p.131-151 [2-52].

RIVERA, Mario. Bosques de tamarugos, un acercamiento etnohistórico para el estudio del paleoclima en el desierto de Atacama. Diálogo Andino, 2018, n. 56, p.119-139.

ROJAS, Fernando; PRIETO, María del Rosario; VILLAGRA, Pablo; ÁlVAREZ, Juan. Deforestación y actividades productivas en los valles del oeste de La Rioja y Catamarca desde mediados del siglo XIX hasta la actualidad. Boletín de Estudios Geográficos, 2014, n. 103, p. 19-57.

SABIO ALCUTÉN, Alberto. Imágenes del monte público, "patriotismo forestal español" y resistencias campesinas, 1855-1930. Ayer. Revista de Historia Contemporánea, 2002, n. 46, p. 123-153.

SALAS LAVAQUI, Manuel. Trabajos y antecedentes presentados al Supremo Gobierno de Chile por la Comisión Consultiva del Norte 1904 (Propuesta al Senado de Proyecto de Ley para la plantación de árboles en la Pampa del Tamarugal, 29/5/1903). Santiago de Chile: Imprenta Cervantes, 1908, 898 p.

SALINAS, Manuel. Proyecto de irrigación de la Pampa del Tamarugal presentado al Congreso Nacional el 29 de mayo de 1903. En RISO-PATRÓN, Francisco. Provincia de Tarapacá. Santiago de Chile: Imprenta de Emilio Pérez L., 1903, p. 36-40.

SANTORO, Calogero. Antiguos cazadores de puna (9.000 a 6.000 a.C.). En HIDALGO, Jorge et al. (eds.), Culturas de Chile. Prehistoria: Desde sus orígenes hasta los albores de la Conquista. Santiago de Chile: Editorial Andrés Bello, 1989, p. 35-55.

SERNAP. Parque Nacional Cutervo. Diagnóstico del proceso de elaboración del Plan Maestro 2009-2014. Lima: Servicio Nacional de Áreas Protegidas por el Estado, $2012,250 \mathrm{p}$.

SIMÓN RUÍZ, Inmaculada. Conflictos ambientales y conflictos ambientalistas en el México porfiriano. Estudios Demográficos y Urbanos, 2010, vol. 25, n. 2, p. 363-394. SIMÓN RUÍZ, Inmaculada. Usos y abusos de los recursos naturales: un estudio de caso en México. En CLAPS ARENES, María y PÉREZ HERRERO, Pedro (coords.), Fiscalidad, medio ambiente y cohesión social en el pensamiento liberal atlántico (siglo $X I X)$. Análisis de Casos. Alcalá de Henares: Instituto de Estudios Latinoamericanos Universidad de Alcalá, 2011, p. 188-212. 
TRELLES, Efraín. Lucas Martínez Vegazo: funcionamiento de una encomienda peruana inicial. Lima: Fondo Editorial Pontificia Universidad Católica del Perú, 1991, $319 \mathrm{p}$.

VAN KESSEL, Juan. La lucha por el agua de Tarapacá; la visión andina. Chungara, 1985, n. 14, p. 141-155.

VELOZO, Luis. Características geomorfológicas de la Pampa O'Brien Pampa del Tamarugal, Tarapacá. Norte Grande, 1974, vol. 1, n. 2, p. 101-111.

VILLALOBOS, Sergio. La economía de un desierto. Tarapacá durante la colonia. Santiago de Chile: Ediciones Nueva Universidad, 1979, 278 p.

YÁÑEZ, José; CANTO, Jhoann. Federico Alberto Faupp. 1867-1928. Gestión Ambiental, 2013, n. 25, p. 1-9.

ZOLEZZI, Mario. Pampa del Tamarugal: La destrucción del monte de La Soledad (ciclo salitrero). Camanchaca, 1993, n. 14, p. 6-8.

Ficha bibliográfica:

CASTRO, Luis. El bosque de la pampa del Tamarugal y la industria salitrera: el problema de la deforestación, los proyectos para su manejo sustentable y el debate político (Tarapacá, Perú-Chile 1829-1941). Scripta Nova. Revista Electrónica de Geografía y Ciencias Sociales. Barcelona: Universidad de Barcelona, 1 de Julio de 2020, vol. XXIV, nº 641. [ISSN: 1138-9788] 